1 Genetic basis of plasticity for forage quality traits in response to water deficit in a diverse

2 germplasm panel of alfalfa

3 Long-Xi Yu ${ }^{1} *$, Bill Boge ${ }^{1}$, Jinguo $\mathrm{Hu}^{1}$, Steven Fransen ${ }^{2}$, Steven Norberg $^{3}$

$4 \quad{ }^{1}$ United States Department of Agriculture-Agricultural Research Service, Plant and Germplasm

5 Introduction and Testing Research; ${ }^{2}$ Irrigated Agriculture Extension and Research Center, Washington

6 State University, 24106 N Bunn Road, Prosser, Washington; ${ }^{3}$ Washington State University Franklin

7 County Extension Office, 404 West Clark Street, Pasco, Washington, USA.

9 * Corresponding author: Long-Xi Yu, United States Department of Agriculture-Agricultural

10 Research Service, 24106 N Bunn Road, Prosser, WA 99350, USA. Phone: 509-786-9259, FAX: 509-

11 786-9277, Email: Longxi.yu@ ars.usda.gov

12 Keywords: Forage quality, drought, GWA, genetic loci, phenotypic plasticity, alfalfa.

13 Short title: Genetic basis of plasticity for forage quality in alfalfa

\title{
14 Abbreviations:
}

$15 \quad \mathrm{ADF}=$ Acid Detergent Fiber

$16 \mathrm{DM}=$ Dry Matter

17 DDM = Digestible Dry Matter

18 DMI $=$ Dry Matter Intake using NDF

19 DMI1 = Dry Matter Intake using NDF and NDFD

20 DDMI = Digestible Dry Matter Intake

$21 \mathrm{ENE}=$ Estimated Net Energy

22 IVDDM30 = 30-hour In Vitro Digestible Dry Matter

23 IVDDM48 = 48-hour In Vitro Digestible Dry Matter

$24 \mathrm{ME}=$ Metabolizable Energy

$25 \quad \mathrm{NEM}=$ Net Energy for Maintenance

$26 \mathrm{NDF}=$ Neutral Detergent Fiber

$27 \mathrm{dNDF}=$ Digestible NDF

$28 \mathrm{dNDF} 30$ = 30-hour Digestible NDF

29 dNDF48 = 48-hour Digestible NDF 
30 NDFD = NDF Digestibility

31 NDFD30 = 30-hour NDFD

32 NEL = Net Energy for Lactation

$33 \quad \mathrm{NFC}=$ Nonfibrous Carbohydrates

34 RFQ = Relative Forage Quality Index

35 RFV = Relative Feed Value Index

36 RUP $=$ Rumen Undegradable Protein

37 TDN $=$ Total Digestible Nutrients

38 TDNL $=$ Total Digestible Nutrients for legume 


\section{Abstract}

43 Plant phenotypic plasticity is the ability of plants to express different phenotypes in response to

44 environmental variations. Genetic bases by which phenotypic plasticity affects plant adaptation to

45 environmental change remain largely unknown. In the present study, we characterized 26 forage

46 quality traits in a panel of alfalfa 198 accessions in a field trial under water deficit gradient. The

47 regression analysis revealed that the values of fiber-related traits decreased, while those among

48 energy-related traits increased, as water deficit increased. Genetic loci for forage quality traits were

49 investigated by Genome-wide association studies (GWAS) under different levels of water deficit.

50 Genetic loci associated with forage quality traits were identified and compared. Similar regions were

51 found between energy-related traits when grand means were used for GWAS. Most of the associated

52 markers were identified under water deficit, suggesting genetic mechanisms for forage quality traits

53 were differ between well-watered and water stressed plants. Although GWAS on forage quality have

54 been reported, we are the first to address the genetic factors for forage quality traits under water deficit

55 in autotetraploid alfalfa. The information gained from the present study will be useful for the genetic

56 improvement of alfalfa with enhanced drought/salt tolerance while maintaining forage quality. 


\section{Introduction}

58 Alfalfa (Medicago sativa L.), "Queen of the Forages", is the most productive and highest quality

59 forage crop. Alfalfa quality reflects its potential to produce a desirable animal response and is directly

60 characterized by laboratory measurements of chemical components including protein, fiber and lignin

61 contents, total digestible nutrients, and other calculated parameters such as: relative feed value (RFV),

62 dry matter intake (DMI) potential and relative forage quality (RFQ). Alfalfa quality is important due to

63 its ability to improve animal performance. Fiber contents such as acid detergent fiber (ADF) and

64 neutral detergent fiber (NDF) are important factors affecting rumen function and digestibility of

65 forage. Alfalfa forage contains $35-55 \% \mathrm{NDF}$, which contributes $\sim 20-30 \%$ of the digestible energy

66 value of alfalfa, the rest coming from non-fiber components (Van Soest, 1982). Relative feed value is

67 a tool that indexes alfalfa quality based on its acid detergent fiber (ADF) and NDF content. The RFV

68 index estimates digestible dry matter (DDM) of the alfalfa from ADF, and calculates the dry matter

69 intake (DMI) potential from NDF. However, RFV has a significant shortcoming because it does not

70 take into account how variations in NDF digestibility affect the energy content or intake potential of

71 alfalfa. Even when harvested at an immature stage, the digestibility of alfalfa fiber can be very

72 different (Goeser and Combs, 2009). In 2004, scientists at the University of Wisconsin designed

73 another index, relative forage quality (RFQ) for estimating forage quality. The RFQ uses fiber

74 digestibility and the total digestible nutrients of the forage to estimate intake (Undersander and Moore,

75 2004). The RFQ index is an improvement over the RFV index as it better reflects the performance on

76 animal fed. The RFQ emphasizes fiber digestibility while RFV uses digestible dry matter intake. The

77 RFV continues to be widely used as an index to assess quality, compare forage varieties, and price

78 forages. However, differences in the digestibility of the fiber fraction can result in a difference in

79 animal performance when forages with a similar RFV index are fed. The RFQ index has been

80 developed to overcome this difference and it takes into account the differences in digestibility of the

81 fiber fraction and can be used to more accurately predict animal performance. 
82 Alfalfa forage quality is affected by environmental factors. Irrigation and an arid climate affect

83 nutritive value of alfalfa hay. Environmental factors such as drought and high salinity are frequently

84 occurred in the arid and semi-arid regions and affect plant growth. Plants have developed several

85 mechanisms to cope with these challenges: including adapting themselves to survive in the adverse

86 conditions (stress-tolerance), and/or changing growth habits to avoid stress conditions (stress-

87 avoidance). Stress-tolerant plants have evolved certain adaptive mechanisms such as phenotypic

88 plasticity to achieve different degrees of tolerance. The extent of phenotypic plasticity often involves

89 in genetic basis subjected to selective pressure, and can evolve a mechanism that facilitates adaptation

90 to environmental changes (Schlichting, 1986). It is unclear whether plant phenotypic plasticity is

91 controlled by specific genes or a result of epistatic interaction during the selection of individual traits.

92 However, genetic diversity and heterozygosity enhance adaptability to variable environments. It is

93 important to identify plant functional traits by which plasticity may play a causal role in plant response

94 to global climate change (Gratani, 2004) or year to year weather changes.

95 In the present study, we evaluated 26 forage quality traits in a panel of 198 alfalfa accessions collected

96 from northern America and dryland regions of other countries. The plants were evaluated in the field

97 under three irrigation regimes: well-watered, mild and severe water deficits. To investigate the genetic

98 base of the forage quality, we applied an integrated framework that merges a QTL mapping approach

99 called "genome-wide association studies (GWAS)" with high-throughput genome sequencing

100 methodologies called "genotyping by sequencing (GBS)" to investigate genomic architecture of

101 phenotypic plasticity of alfalfa quality traits under a gradient of water deficits. The ultimate goal is to

102 gain a better understanding on genetic bases by which water deficit affects phenotypic plasticity of

103 forage quality and to identify genetic regions associated with forage quality traits in alfalfa under a

104 deficit irrigation gradient. The identified DNA markers that are significantly associated with the traits

105 will be used for marker-assisted selection and would facilitate breeding for high quality alfalfa 
106 varieties based on genetic potential and reduce the confounding of environmental conditions with

107 traditional breeding methods.

108 Materials and Methods

109 Plant Materials

110 A panel of germplasm composed of 198 alfalfa accessions selected from the USDA-ARS National

111 Plant Germplasm System (NPGS) alfalfa collection was used in this study. Majority of the panel was

112 collected from Northwest regions of US and Canada including Manitoba, Idaho, Montana, Nebraska,

113 Washington, North and South Dakota. British Columbia, and Saskatchewan and the remaining was

114 collected from dry regions of different countries including Afghanistan, Algeria, Bulgaria, China,

115 Germany, India, Lebanon, Oman, Russia, Spain, Turkey, and Yemen.

116 Field experiments

117 Alfalfa accessions were planted on the Roza Farm (GPS point is 46.289391, -119.725428) at the

118 Irrigated Agriculture Research and Extension Center, Washington State University, Prosser WA, in

119 2016. Field experiments used a randomized complete block design. Each block contains 9 plants with

12015 inch between rows and 10 inch between plants. They were irrigated regularly until the plant size

121 was uniform (day 35-40). Subsequently, the control plants were watered regularly while water deficits

122 were applied to the stressed plants by withholding water during the dry season (June-September).

123 Periodic irrigation was applied as necessary for the mild stress. The exact watering interval was

124 determined during the trial through visual evaluation of wilting of the plants. No water was applied

125 until harvesting for the severe drought stressed plants. 
127 A subset of samples from the first cuttings was used for quality analyses. Plant samples were dried in

128 oven at $60^{\circ} \mathrm{C}$. They were then ground in Wiley Mill (Thomas Scientific, US) prior to the final grinding

129 in Cyclotec 1093 sampling mill (Foss, Hillerød, Denmark) through a $1 \mathrm{~mm}$ screen. Sample powders

130 were loaded and measured by Near Infrared Reflectance Spectroscopy (NIRS). Spectra were collected

131 by a scanning monochromator (FOSSNIR Systems 6500, Silver Spring, MD, USA) in the spectral

132 range from 400 to $2500 \mathrm{~nm}$. A NIRS Consortium equation 13AH50.2-eqa was used to predict quality

133 factors.

\section{Statistical analysis}

135 Phenotypic data were subjected to an analysis of variance (ANOVA), testing the variation among

136 accessions for each treatment conditions. To estimate phenotypic plasticity, a plasticity index (PI) was

137 calculated according to Valladares et al., (2000) as follow:

$$
P I=\left(M_{\max }-M_{\min }\right) / M_{\max }
$$

138 Where $M_{\max }$ is the highest value of the treatment average and $M_{\min }$ is the lowest value of treatment

139 average for a specific trait in the population.

140 Genotyping by sequencing

141 Genotyping-by-sequencing was carried out as described Elshire et al. 2011). Briefly, DNA extracted

142 from original plants of the association panel was digested by methylation sensitive restriction enzyme,

143 EcoT221. GBS libraries were then prepared with barcode adapters. Libraries were sequenced in the

144 Illumina Hi-Seq2000 instrument using 100-base single-end sequencing with 2 lanes at Cornell

145 University Sequencing facility (Ithaca, NY). 
146 After quality check using FastQC (http://www.bioinformatics.babraham.ac.uk/projects/fastqc/), the

147 sequence reads were proceeded using the FreeBayes pipeline adapted for tetraploid alfalfa for

148 genotype calling as described previously (Yu et al. 2017).

149 Genome-wide association analysis

150 The filtered marker data were loaded to TASSEL (Bradbury et al. 2007) for GWAS. A mixed linear

151 model was used for analyzing marker-trait association. The Kinship (K) and Q matrices were used for

152 controlling population structure during association analysis. Marker's p-value was used to determine

153 the significance of marker-trait association. A false discovery rate (FDR) of 0.05 was used as a

154 threshold for significant association (Benjamini and Hochberg, 1995).

\section{Results}

156 Phenotypic variations of forage quality traits

157 The analysis of variance for 26 quality traits was carried out among the panel of germplasm and the

158 result is presented in Table 1 . The sum of squares varied from 0.29 in NEL to 130770.31 in RFV. The

159 differences of most of the traits are statistically significant at the probability $<0.0001$ level. The

160 estimated parameters varied from $0.41(\mathrm{NEG})$ to $164.71(\mathrm{RFV})$. The differences for the parameter

161 estimates are statistically significant at the probability $<0.0001$ level for all the traits. Regressions of

162 phenotypic evaluations showed significant effects of water deficit on forage quality (Fig. 1). The

163 values of fiber-related traits, including ADF, aNDF, dNDF30, dNDF48 decreased as water deficit

164 applied (Fig. 1, A1-4). Water deficit also decreased the contents of fat, RUP, IVDDM30 and NDFD48

165 (Fig. 1 B1-4), and slightly decreased TDNL, protein, IVDDM48 and lignin (Fig. 1, C1-4). Whereas,

166 the values for energy-related traits include DM, ME, NEL, TDN, NEM, NEG, DRYMI, RFV, ENE,

167 DDM, NFC and DMI1 increased by water deficit (Fig. 1 D1to F4). Water deficit slightly increased

168 RFQ and ash (Fig. 1, G1-2). 
169 Correlation coefficient was also investigated among the quality traits under well-watered and water

170 deficit conditions. Fig. 2 shows the heat maps of correlations among 26 quality traits under well-

171 watered (Fig. 2 A), mild (Fig. 2 B) and severe (Fig. 2 C) water deficits. Overall, negative correlations

172 were found between DM, ADF, aNDF, ash, lignin, RUP and energy-related traits. Whereas crude

173 protein, IVTDMD30/48 were positively correlated with energy traits. Higher correlations were found

174 among energy traits under all water conditions. The correlations between NDFD48, NFC, TDNL and

175 energy traits increased when water deficits applied.

176 Phenotypic plasticities of quality traits

177 Phenotypic plasticity was estimated by calculating the PI for each trait in the given accession under

178 well-watered and water deficit conditions as described in the section of Materials and Methods.

179 Overall, higher PIs were found in water deficit conditions compared to well-watered control except

180 lignin, fat and protein (Fig. 3, Table 2). Within the water stress treatments, higher PIs were found in

181 the mild stress than those in the severe stress for most of the quality traits. Among them, the highest

182 PIs were found in RFQ with $0.55,0.77$ and 0.75 for the control, mild and severe drought conditions,

183 respectively (Table 2, Top). The lowest PIs appeared in DM with 0.02, 0.04 and 0.03 for control, mild

184 and severe drought, respectively (Table 2, bottom). The rest of the traits showed higher PIs in severe

185 drought compared to the mild treatment. The PI values were very similar between DRYMI and aNDF,

186 ENE and NEL, and TDN and ME.

188 The mean values of 26 forage quality traits were used for cluster analysis. Two large clusters and 14

189 subclusters were classified as showing in Fig. 4. The first large cluster contained 8 subclusters. Most

190 of germplasm in this cluster were collected from cultivars from US and Canada and their quality traits

191 such as crude protein and RFV were relatively higher, so we named it as the higher forage quality 
192 cluster (Fig. 4, top cluster). Two checks, Rambler and Saranac, susceptible to salt/drought are in this

193 cluster (Fig. 4, subclusters 5 and 8). The bottom cluster was furtherly classified into 6 subclusters

194 containing germplasm collected worldwide, including old cultivars and landraces with relatively lower

195 forage quality (Fig. 4, bottom cluster). Three salt/drought resistance checks, Malone, Mesa Sirsa and

196 Wilson are in this cluster (Fig. 4 subcluster 9). There was a trend that alfalfa germplasm with

197 resistance to salt/drought had lower forage quality, while higher quality was found in the susceptible

198 alfalfa germplasm.

199 Genome-wide association for forage quality

200 The combinations of the filtered GBS markers and phenotypic data of 26 quality traits were analyzed

201 by GWAS using a mixed linear model. The results of marker-trait association for well-watered control

202 (A), mild (B) and severe (C) water deficits were illustrated in quantile-quantile plots (QQ) (Fig. 5).

203 The QQ plots shows the expected distributions of association test statistics (X-axis) across thousands

204 of SNPs compared to the observed values (Y-axis). Any deviation from the X=Y line implies a

205 consistent difference between expected and observed across the whole genome. In the present study,

206 as showing in Fig. 5, solid lines represent stress treatments match with the expected line until they

207 sharply curve at the end, representing a small number of true associations among majority of

208 unassociated SNPs. The significances of marker-trait association were presented in negative log P-

209 values. Overall, lower significance was obtained in the control (Fig. 5 A) while higher significances

210 were obtained in the stress (Fig. 5 B and C) with highest in the mild stress Fig. 5 B). Significances

211 were only found in TDNL, NDFD48 and ME under well-watered condition (Fig. 5 A), whereas most

212 significances were found in majority of the traits under the mild stress (Fig. 5 B) with highest in

213 dNDF30 and 48. The highest association was found in ash in the severe stress (Fig. 5 C), however, the

214 level of significances was lower by the severe stress compared to that of the mild stress (Fig. 5 B).

215 More detailed profile of marker-trait association is presented in Manhattan plots (Fig. 6). Of 26 traits 
analyzed, most significant marker-trait associations were found in ash, NDFD48, dNDF30, dNDF48,

217 NFC and TDNL under mild water stress (Fig. 6 B, E, H, K, N and Q). Similar association profiles

218 were found in the severe stress, but the marker's significances were lower for the same traits (Fig. 6 C,

219 F, I, L, O and R) compared to the mild stress. Whereas no or less significant markers were shown

220 under control and severe stress conditions (Fig. 6 remaining panels). Among those, the highest

221 significant markers were identified in ash and they were located on chromosomes 2, 6, 7 and unknown

222 chromosome (U) (Fig. 6 B). Similarly, Significant markers associate with NDFD48 were also

223 identified on same chromosomes (Fig. 6 E) under mild stress but not in control and severe stress (Fig.

$2246 \mathrm{D}$ and F, respectively). Significant markers were also found in dNDF30 and dNDF48 and they were

225 located on chromosomes 1, 2, 3 and 8 (Fig. $6 \mathrm{H}$ and K, respectively). Mild stress also triggered

226 marker-trait associations in NFC and TDNL (Fig. $6 \mathrm{~N}$ and Q, respectively). Significant markers

227 associated with NFC were located on chromosomes 2, 6 and 7 (Fig. 6 N). while markers associated

228 with TDNL were located on chromosomes 2 and 6 (Fig. 6 Q).

229 When phenotypic means were used for marker-trait association, similar association profile was found

230 among DRIMI, DMI1, RFV, and RFQ (Fig. 7.1 A-D), and most significant markers were identified on

231 chromosome 8 and unknown chromosome (Chr. U). Similar profiles were also found among ADF,

232 DDM, TDN, ENE, ME, NEM, NEG and NEL (Fig. 7.1 E-L) and most significant markers were

233 located on chromosome 8 and $\mathrm{U}$. The same was true between DM and moisture (Fig. 7.1 M and N).

234 Although similar association patterns were found between in vitro dry matter digestibility $30 \mathrm{~h}$ and $48 \mathrm{~h}$

235 (IV30 and IV48, respectively), none was statistically significant, neither in IV30 nor in IV48 (Fig. 7.1

$236 \mathrm{O}$ and P). Different association profiles were shown among the remaining traits (Fig. 7.2 A-O).

237 Among those, significant markers were found on chromosomes 1, 2, 3 and 8 for dNDF48 (Fig. 7.2 C),

238 whereas no significant marker was identified in dNDF30 (Fig. 7.2 B). One significant marker was

239 identified in dNDF48 but its chromosome location was unknown (Fig. 7.2 D). Significant markers 
240 were identified on chromosomes 3 and 5 for lignin content (Fig. 7.2 E). A marker was identified for

241 NFC, with unknown chromosome position (Fig. 7.2 F). Seven markers were highly significantly

242 associated with ash and they were located on chromosomes 1, 2, 3, 7 and 8 (Fig. 7.2 J). Only one

243 marker on chromosome 4 was significantly associated with fat (Fig. 7.2 K).

244 Common markers identified among multiple quality traits and different treatments

245 Despite different loci identified among quality traits, common marker loci were found among multiple

246 traits (Table 3). Marker S1_110050725 on chromosome 4 identified in CTL for ADF also significantly

247 associated with other 10 traits including DDM, ENE, IVDMD30, IVDMD48, ME, NEG, NEL NEM,

248 Protein and TDN (Table 3, top row). Similarly, markers S1_305729816 for DMI1 in CTL also

249 associated with 6 other traits: IVDMD30, IVDMD48, NDFD48, RFQ, TNDL and protein. Marker

250 S1_231443201 for ADF shared its association with DDM, ENE, ME, NEG, NEL, NEM, TDN and

251 TDNL. Four markers (S1_197238737 - 90) at the same locus on chromosome 6 and unknown marker

252 S1_292679040 identified for ash in the mild stress were also associated with 6 other traits. Markers

253 S1_351118210 and S1_276968305 identified in CTL for IVDMD48 and ash, respectively, were

254 significantly associated with 5 other traits. Marker S1_174013573 identified in the severe stress for

255 DMI1 were also associated with DRYMI, fat, RFQ and RFV. There were eight markers associated ash

256 were also associated with NDFD48, NFC and TDNL (Table 3). There were nine, eighteen and fifty-

257 five markers were shared their associations with three, two and one traits, respectively. The remaining

258 markers were independently associated with one trait (Table 3, bottom part). Most of the high

259 significant markers with lower P-value and higher $\mathrm{R}^{2}$ are among of common markers, suggesting these

260 markers may have major effects on the respective traits. Among those, ten markers were associated

261 with the same three traits (NDFD48, NFC and TDN). The P-values of these markers ranged from

262 4.01E-08 (S1_21394491) to 5.79E-16 (S1_197238737) and the marker's $\mathrm{R}^{2}$ ranged from 0.22 to 0.38,

263 respectively (Table 3). 
264 To oversee the genetic architecture of the population under different treatments, we compared markers

265 significantly associated with CTL, mild and severe drought treatments with those identified using

266 mean values of all treatments. Among 68 markers identified in the control, 17 were also identified in

267 the mean (Fig. 8 A). Of 70 significant markers identified in the mild stress, only 10 were also

268 identified in the mean (Fig. 8 A). Among 67 markers identified in severe drought, 20 were also found

269 in the mean (Fig. 8 A). We have also compared the common markers identified among the three

270 treatments directly. There were 3 common markers between each pair of treatments (Fig. 8 B). Only 2

271 markers were found in all three treatments (Fig. 8 B).

Assignment of significant markers to annotated genes

273 Using the flanking sequences of the significant markers, we performed a BLAST search to identify

274 potential candidate genes linked to significant marker loci. Of significant markers identified, 23

275 markers were found to be linked to known genes in the M. truncatula genome Mtv4.2 (Table3). Of

276 those identified under well-watered condition (CTL), marker S1_305729816 and S1_176594850

277 associated with DMI1 were linked to a programmed cell death and hypothetic proteins, respectively.

278 Marker S1_371197359 associated with ash was linked to a reticulon-like protein B2. Two markers

279 (S1_153379823 and S1_ 153379823) located at the same locus associated with NFC was linked to

280 cadmium/zinc transporting ATPase. Of those identified under mild water deficit, many markers were

281 associated with ash. Among them, marker S1_292679040 was linked to cytochrome P450 family

282 protein; marker S1_300540244 was linked to UDP-glucosyltransferase; S1_311409163 was linked to

283 exostosin; S1_62932631 was linked to helix loop helix DNA-binding domain protein; S1_309228882

284 was linked to carotenoid cleavage dioxygenase; S1_130145842 was linked to RING zinc finger

285 protein; S1_294827153 was linked to auxin-binding protein ABP19a; S1_274178328 was linked to E3

286 ubiquitin protein ligase XBOS32; S1_319319782 was linked to IQ calmodulin-binding motif protein;

287 and S1_380790483 was linked to Feronia receptor-like kinase. Three markers, S1_20593175, 
S1_368369179 and S1_92116984 associated with dNDF30 and dNDF48 were linked to LRR-

receptor-like kinase, HASTY1 and OPT family oligopeptide transporter, respectively. Of those

290

identified under severe water deficit, markers S1_108148173, S1_259198355 and S1_261323300 were

291 linked to TIR-NBS-LRR resistance protein, interferon-induced guanylate-binding protein and

292 peroxidase family protein, respectively. Anther marker S1_310998070 associated with fat was linked

to RNA-binding (RRM/RBD/RNP motif) protein.

\section{Discussion}

Phenotypic variations of forage quality among alfalfa accessions

296 Near Infrared Reflectance Spectroscopy (NIRS) has become popular for use in measuring forage

297 quality factors, since relatively precise results can be obtained fast with a proper NIRS. In the present

298 report, we used NIRS results for 26 forage quality factors including protein, fibers, energy and

299 minerals and performed cluster analysis on phenotypic variations of forage quality among 198 alfalfa

300 accessions. A majority accessions were classified into the higher quality cluster, among those, two

301 drought sensitive varieties were in this cluster. The remaining accessions were grouped into the lower

302 quality cluster where three drought tolerance varieties were in this cluster. There is a trend that

303 drought sensitive varieties have relative higher quality than those with drought tolerance. It suggests

304 that breeding for drought tolerant alfalfa may result quality penalty as the crop diverts energy to

305 implementing drought resistance. Therefore, quality factors should be considered when breeding for

306 abiotic tolerance.

307 Commercial markets are seeking common means for estimating forage quality in terms of its value as

308 a feed for livestock. Currently, RFV is the most popular quality measurement and is accepted by hay

309 buyers. Dairy's often retest hay and look for NEL, CP and aNDF are excellent indicators of energy,

310 protein and fiber, respectively. In this report, water deficit significantly decreased aNDF and slightly 
311 decreased CP but increased NEL (Fig. 1). Relative Feed Value is calculated from ADF an old estimate

312 of digestible dry matter and NDF and estimate of dry matter intake that is still used (Undersander and

313 Moore, 2004). In the present study, we found a high positive correlation $\left(\mathrm{R}^{2}=9.405\right)$ between $\mathrm{RFV}$

314 and the mean of 26 quality factors (Fig. 9 A). However, the RFV is not a good measurement of NDF

315 digestibility. The RFQ index has been developed to overcome this shortage as it takes into

316 consideration the differences in digestibility of the fiber fraction and can be used to more accurately

317 predict animal performance. We therefore performed correlation analysis between RFQ and the mean

318 of 26quality factors and obtained very high correlation coefficient $\left(\mathrm{R}^{2}=0.9946\right)$ between them (Fig. 9

319 B). Our results support that the RFQ is more accurate in estimating overall forage quality compared to

320 the RFV. Differences in the digestibility of the fiber fraction can result in a difference in animal

321 performance even if the forages with the same RFV are fed. The RFQ index is an improvement over

322 the RFV index for estimating forage quality as it better reflects the performance of animal fed the

323 forage.

324 On the other hand, neither RFV nor RFQ does not include protein concentration or physical

325 characteristics. Protein and physical characteristics are important factors for evaluating forage quality.

326 To understand the relationships between those factors, in the present study, we analyzed the

327 correlations between protein content and the RFV (Fig. 9 C). Although positive correlations were

328 found between protein and the RFV, the correlation was moderate $\left(\mathrm{R}^{2}=0.6827\right)$ between them. Similar

329 correlation coefficient $\left(\mathrm{R}^{2}=0.6447\right)$ was also found between the RFQ and the protein content (data not

330 shown). Therefore, protein and physical characteristics should be evaluated along with RFV and RFQ

331 for a complete assessment of forage quality.

332 Mild drought intends to decrease fiber content and improve digestibility in alfalfa 
333 Production of alfalfa for maximum yield and quality requires an understanding of how environmental

334 and cultural factors influence crop growth and development. These factors include growing conditions,

335 stage of maturity at harvest, and climate conditions. Causations exists between the environment, plant

336 response, and nutritive value. In general, yield and forage quality are inversely related. Any factor that

337 retards plant development tends to promote the maintenance of forage quality. If a plant is stressed

338 during growth, a shorter, finer-stemmed, leafier alfalfa is often produced. On the other hand, factors

339 that accelerate growth, such as drought and high temperature, tend to have a negative impact on forage

340 quality. Alfalfa is relatively drought tolerant because its deeper root systems allow alfalfa to absorb

341 deep soil water and quickly recover from drought conditions. However, when transpiration exceeds

342 water absorption, a stress is imposed on the plant influencing metabolism, development, growth, and

343 ultimately yield. Water deficit promotes a reduction in vegetative growth and promote early maturity.

344 It has been suggested that mild drought stress may be beneficial for forage quality as alfalfa as

345 drought-stressed alfalfa will accelerate its shift to reproductive growth (Cassida, 2012). Once a stem

346 has flowered, there will be little additional growth in the stem. Stem internode growth is suppressed,

347 resulting in a greater proportion of leaves on shorter stems. In a short term of drought stress, the

348 greater proportion of leaves in the drought-stressed forage improves feed quality and digestibility.

349 However, if drought stress has been too severe, and for an extended period, plant stress is permanent

350 and may not be recovered.

351 Alfalfa fiber is consisted of three components: cellulose, hemicellulose and lignin. Increasing fiber

352 content of a forage generally decreases its energy content. Of the fiber fractions, cellulose is the major

353 compound digested by the animal while lignin is virtually indigestible in both the rumen and lower

354 intestines. In our study, drought decreased significantly both ADF and NDF, which in turn increased

355 energy-related traits such as TDN, ENE, DDM, NFC, RFV and RFQ (Fig. 1). Drought affects forage

356 quality as cell wall remodeling is a common plant response to abiotic stresses. Biomass composition 
was drastically altered due to drought stress, with significant reductions in cell wall and cellulose

content. Cell wall structural rigidity was also affected by drought conditions, substantially higher

cellulose conversion rates were observed upon enzymatic saccharification of drought-treated samples

360

with respect to controls. Both cell wall composition and the extent of cell wall plasticity under drought

361

varied extensively among all genotypes, but only weak correlations were found with the level of

drought tolerance, suggesting their independent genetic control.

Genetic architecture of forage quality under well-watered and water deficit conditions

364

365

366

367

368

369

370

371

372

373

374

375

376

377

378

379

Among markers associated with forage quality under deferent irrigation episodes, a small number of the markers were in common between well-watered and water deficit conditions, while most of them responded independently to the treatments (Fig. 6), suggesting their independent genetic control.

However, when phenotypic mean was used for GWAS, similar association patterns were found amongst energy-related traits, including DDM, TDN, ENE, ME, MEM, NEG and NEL, and traits of DRYMI, DMI1, RPV and RFQ (Fig. 7). The genetic responses to mean values of these traits may suggest common genetic bases among them. This is logical as these traits measure similar forage quality factors.

In the GWAS, we only find nine associated markers that have consistent effects across water deficit treatments (Fig. 8B). The rests were differentially associated with respective treatments. Interestingly, about 2 folds of markers were associated with mild water deficit compared to those identified by severe water deficit (Fig. 8B), suggesting that mild water deficit may trigger more genetic responses than the severe stress and the control. Drought tolerance is a complex trait and is affected by genetic and environmental interaction $(\mathrm{GxE})$. This was dominated both at the trait level and for allelic effects of significantly associated causal variants. Therefore, we cannot directly address whether conditionally neutral alleles accumulate genetic variation at a faster rate than constitutively expressed genetic 
variation. For example, the number of significant markers were significantly reduced when severe water deficit applied compared to mild stress and well-watered control. This may indicate that the plants shut down some metabolic pathways to save energy for drought avoidance under severe drought stress.

\section{Putative candidate genes associated with forage quality}

Among 23 annotated genes associated with forage quality traits, three genes were identified under well-watered condition (Table 3). The programmed cell death (PCD) protein was associated with

DMI1, CP, RFQ, TDNL, NDFD48, IVTDMD-30 and -48. PCD in plants is a crucial component of

development and defense mechanisms. PCD has multiple functions and regulates a complex molecular network in plant development (For review see Daneva et al., 2016). Its associations with multiple traits in the present study suggested that PCD involved in regulating forage quality in multiple ways.

Reticulon-like protein B2 (RTNLB2) was associated with ash and TDNL. It has been reported that the

RTNLB2 is located in endoplasmic reticulum and plays a role in regulating receptor transport to plasma membrane in Arabidopsis (Lee et al., 2011). Another putative candidate, cadmium/zinc transporting ATPase ( $\operatorname{cadA})$ was associated with NFC. The cadA is located in vacuole and involved in cadmium and zinc or cobalt transport and may have a detoxification function through a vacuolar sequestration in Arabidopsis (Mishra et al., 2017). Fourteen genes were identified under mild water deficit (Table 3). Of those, cytochrome P450 (CYP) was associated with ash, dNDF48, NDFD48, 398 NCF and TDNL. P450 family protein is a large enzymatic protein family in plants and play a role in 399 plant development and biotic and abiotic stresses responses (Xu et al., 2015 for review). UDP400 glucosyltransferase (UGT) was associated with ash, NDFD48, NFC and TDNL. UGT plays a role in 401 abscisic acid (ABA) homeostasis which regulates the plant response to environmental stresses such as 402 drought cold and salinity (Dong et al., 2014). A RING zinc finger protein (RZFP) was associated with 
404 Arabidopsis, AtRZFP enhanced salt and osmotic tolerance mediated by enhancing ROSs scavenging,

405 maintaining $\mathrm{Na}^{+}$and $\mathrm{K}^{+}$homeostasis, adjusting the stomatal aperture to reduce water loss, and

406 accumulating soluble sugars and proline to adjust the osmotic potential (Zang et al., 2016). An E3

407 ubiquitin protein ligase XBOS32 was associated with ash and NFC. There is evidence to suggest that

408 E3 Ub-ligases can control protein turnover by modification of UPS-related proteins and contributes to

409 nuclear proteome plasticity during plant responses to environmental stress signals (Serrano et al.,

410 2018). An IQ calmodulin-binding motif protein was associated with ash. It has been reported that an

411 IQ calmodulin-binding motif protein encoded by a gene of osa-mir369c classified as a small RNA

412 family involved in impacting growth regulation under several environmental stresses such as

413 temperature, drought and salinity in rice (Gao et al. 2010). The identification of calmodulin-binding

414 proteins in the present study supports the assumption that this regulator is important player in response

415 to abiotic stress through the calcium-signaling pathway (Ranty et al., 2006). Five genes were identified

416 under severe water deficit (Table 3). Among them, the TIR-NBS-LRR protein was associated with ash

417 and NFC. The plant TIR-NBS-LRR gene family contains a large class of disease resistance genes

418 (DeYoung and Innes, 2006). The identification of the TIR-NBS-LRR genes in the present study

419 suggests that it also involve in drought response in alfalfa. A similar finding of drought-related role for

420 a NBS-LRR has also been reported in Arabidopsis where overexpression of the NBS-LRR gene

421 ADR1 enhanced drought tolerance (Chini et al., 2004). It has been suggested that a signaling network

422 exists between disease resistance and drought tolerance, and ADR1 may be involved in signal

423 transduction in this network (Chini et al., 2004). An interferon-induced guanylate-binding protein

424 (IIGBP) was associated with ash and NFC. The IIGBP is a GTPase induced by interferon and plays a

425 role in directing inflammasome subtype-specific responses and their consequences for cell-

426 autonomous immunity against a wide variety of microbial pathogens (Kim et al., 2016). A peroxidase

427 family protein was associated with ash and NFC. The peroxidase responses are directly involved in the

428 protection of plant cells against adverse environmental conditions. Several roles have been attributed 
to plant peroxidases in response to biotic and abiotic stresses. They may have a cell wall cross-linking

430 activity during plant defense mechanisms (Chen et al., 2002). A RNA-binding (RRM/RBD/RNP

431 motif) protein was associated with fat under severe water deficit. RNA-binding proteins (RBP) play

432 important roles in post-transcriptional gene regulation. Recent investigation of plant RBPs

433 demonstrated that, in addition to their role in diverse developmental processes, they are also involved

434 in adaptation of plants to various environmental conditions (Lorkovic, 2009 for review). Although the

435 remaining genes identified under water deficit do not have direct roles in stress responses, they involve

436 in diverse processes in cell developments. For instance, Auxin-binding protein (ABP) was associated

437 with ash, NFC and TDNL under mild water deficit. It has been suggested that ABP1 in Arabidopsis is

438 involved in a broad range of cellular responses to auxin, acting either as the main regulator of the

439 response, such as seen for entry into cell division or, as a fine-tuning device as for the regulation of

440 expression of early auxin response genes (For review, see Tromas et al., 2010).

\section{Conclusion}

442 In the present study, we evaluated 26 forage quality traits in a panel of 198 alfalfa accessions in the

443 field trial under deficit irrigation gradience: well-watered, mild and severe water deficits. Phenotypic

444 plasticities of forage quality traits were analyzed using the three irrigation treatments. Water deficit

445 decreased fiber contents and enhanced energy-related traits. Higher correlations were found among the

446 energy-related traits and the correlation coefficients increased when water deficit was applied. The

447 highest correlation coefficient was obtained between RFQ and the quality mean, supporting that the

448 RFQ is more accurate in estimating overall forage quality compared to the RFV.

449 Genetic architectures of phenotypic plasticities for 26 forage quality traits were investigated by

450 GWAS under different irrigation treatments. Genetic markers associated with forage quality traits

451 were identified and genetic regions responsive for the respective traits were compared. Similar regions 
were found between energy-related traits when mean values were used for GWAS. Significant

markers associated with forage quality under water deficit were identified with highest significant

454 marker-trait association in the mild stress. Only a small number of markers were commonly associated

455 with all treatments. Most of the associated markers were independent to the different levels of water

456 deficit treatments, suggesting genetic controls for forage quality traits were independent to the stress

457 treatment. Although GWAS on forage quality have been reported, we are the first to address the

458 genetic base of phenotypic plasticity of forage quality traits under water deficit. The information

459 gained from the present study will be useful for the genetic improvement of alfalfa with enhanced

460 drought/salt tolerance while maintaining forage quality.

\section{Acknowledgements}

462 This work was supported partially by The United State Department of Agriculture NIFA_AFRP

463 Grant Number 2015-70005-24071 and the Agriculture Research Service base fund. We thank Mrs.

464 Martha Rivera for her technical assistance and data collection.

\section{Author Contributions}

466 LXY planned and designed the research. BB and SF performed field work and forage quality tests.

467 LXY, JH and SN wrote the manuscript.

\section{Conflict of Interest Statement}

469 The authors declare that the research was conducted in the absence of any commercial or financial 470 relationships that could be construed as a potential conflict of interest.

\section{References}


Benjamini, Y. and Hochberg, Y. (1995) Controlling the false discovery rate: a practical and powerful approach to multiple testing. J. R. Stat. Soc. 57, 289-300.

Bradbury, P.J., Zhang, Z., Kroon, D.E., Casstevens, T.M., Ramdoss, Y., and Buckler, E.S. (2007). TASSEL: software for association mapping of complex traits in diverse samples. Bioinformatics 23. doi: 10.1093/bioinformatics/btm308. Cassida, K. (2012) Managing alfalfa during drought. Michigan State University Extension accessed at http://www.canr.msu.edu/news/managing_alfalfa_during_drought.

Chen EL, Chen YA, Chen LM, Liu ZH. (2002) Effect of copper on peroxidase activity and lignin content in Raphanus sativus, Plant Physi. Bioch. 40:439-444. established by enhanced expression of the CC-NBS-LRR gene, ADR1, requires salicylic acid, Cell Death in Plant Development. Annu Rev Cell Dev Biol. 32:441-468.

DeYoung BJ1, Innes RW. (2006) Plant NBS-LRR proteins in pathogen sensing and host defense. Nat Immunol. 7:1243-1249. glucosyltransferases play a crucial role in abscisic acid homeostasis in Arabidopsis. Plant Physi. 165:227-289. 
Gao, P., Bai, X., Yang, L., Lv, D., Li, Y., et al. (2010). Over-expression of osa-MIR396c decreases salt and alkali stress tolerance. Planta 231, 991-1001, doi: 10.1007/s0.0425-010-1104-2.

Garrison, E., and G. Marth. 2012. Haplotype-based variant detection from short-read sequencing. ArXiv12073907 Q-Bio.

Goeser JP1, Combs DK. (2009) An alternative method to assess 24-h ruminal in vitro neutral detergent fiber digestibility. J Dairy Sci. 92(8):3833-41. doi: 10.3168/jds.2008-1136.

Gratani L. (2014) Plant phenotypic plasticity in response to environmental factors. Adv. Botany. 2014:1-17, http://dx.doi.org/10.1155/2014/208747. intracellular trafficking and activity of the fls2 immune receptor. Pant Cell. 23:3374-3391.

510 genome organization. Trends Plant Sci. 14:229-236.

511 Mishra S, Mishra A and Küpper H (2017) Protein Biochemistry and Expression Regulation of 512 Cadmium/Zinc Pumping ATPases in the Hyperaccumulator Plants Arabidopsis halleri and $513 \quad$ Noccaea caerulescens. Front. Plant Sci. 8:835. doi: 10.3389/fpls.2017.00835.

514 Ranty, B., Aldon, D. and Galaud, J-P. (2006). Plant calmodulins and calmodulin-related proteins: $515 \quad$ Multifaceted relays to decode calcium signals. Plant Signal. \& Behav. 1, 96-104. 
Schlichting CD (1986) The Evolution of Phenotypic Plasticity in Plants. Annual Review of

$517 \quad$ Ecology and Systematics. 17: 667-93. doi:10.1146/annurev.es.17.110186.003315.

518 Serrano I, Campos L and Rivas S (2018) Roles of E3 Ubiquitin-Ligases in Nuclear Protein

519 Homeostasis during Plant Stress Responses. Front. Plant Sci. 9:139. doi:10.3389/fpls.2018.00139.

520 Sultan SE (2000) Phenotypic plasticity for plant development, function and life history. Trends in

521 Plant Science. 5 (12): 537-42. PMID 11120476. doi:10.1016/S1360-1385(00)01797-0.

522 Undersander, D., and Moore J.E. (2004) Relative forage quality. Focus on Forage, accessed at 523 http:// www.uwex.edu/ces/crops/uwforage/RFQvsRFV.htm\#home.

524 Valladares F, Martınez-Ferri E, Balaguer L, Perez-Corona E, Manrique E. 2000. Low leaf-level 525 response to light and nutrients in Mediterranean evergreen oaks: a conservative resource-use 526 strategy? New Phytologist 148: 79-91.

Valladares F, Gianoli E, Gomez JM. 2007. Ecological limits to plant phenotypic plasticity. New $528 \quad$ Phytologist 176: 749-763. 
Yu L-X., Zheng P., Bhamidimarri S., Liu X -P. and Main D. (2017) The Impact of Genotyping-bydoi: 10.3389/fpls.2017.00089.

\section{$546 \quad$ Figure legends}

547 Fig. 1. Bivariable plots for forage quality traits under well-watered (1), mild (2) and severe (3) water 548 deficits (X-axis). Phenotypic values of each trait are presented by Y-axis.

549 Fig. 2. Heat plots of correlation coefficient among quality traits under well-watered control (CTL), 550 mild water deficit (Mild) and severe water deficit (Severe).

551 Fig. 3. Phenotypic plasticities of 26 forage quality traits in response to mild and severe water deficits 552 and well-watered control in alfalfa.

553 Fig. 4. A hierarchical cluster obtained using farthest neighbor method with phenotypic values of all 554 quality traits evaluated in the present study. Accessions (PIs) were clustered into 2 clusters (High and 555 low quality clusters) and 14 subclusters. The high quality cluster contains 8 subclusters with relatively 556 higher quality. The low quality cluster contains 6 subclusters with relatively lower quality. Two 557 checks, "Saranac" and "Rambler", susceptible to salt/drought stress were clustered into the high 
quality cluster (Subclusters 5 and 8, respectively), and three drought/salt resistance checks, "Mesa

559 Sirsa", "Wilson" and "Malone" were clustered into the low quality cluster (Subcluster 9).

560 Fig. 5. Quantile-quantile plots of marker-trait association from GWAS for forage quality traits under

561 well-watered (A), mild (B) and severe (C) water deficits in the alfalfa association panel. The expected

562 (solid lines) against observed (dot lines) $-\log _{10} \mathrm{p}$-values are presented on $\mathrm{X}$-axis and Y-axis,

563 respectively. Each color curve represents a quality trait as showing at the bottom of the figures.

564 Fig. 6. Manhattan plots of marker-trait association of six most significant quality traits under well-

565 watered control (CTL), mild water deficit (Mild) and severe water deficit (Severe). The X-axis

566 presents chromosome positions of loci based on the reference genome of M. truncatula (Mt4.0, v1).

567 The Y-axis shows negative $\log$ (P-values) of marker-trait association. Chromosome numbers were

568 assigned and illustrated at the bottom of the figures.

569 Fig. 7.1. Comparison of association profiles of forage quality traits using means of three irrigation

570 treatments. The X-axis presents chromosome positions of loci based on the reference genome of $M$.

571 truncatula (Mt4.0, v1). The Y-axis shows negative log (P-values) of marker-trait association.

572 Chromosome numbers are illustrated by colors at the bottom of the figures.

573 Fig. 7.2 Comparison of association profiles of forage quality traits using means of three irrigation

574 treatments. The X-axis presents chromosome positions of loci based on the reference genome of $M$.

575 truncatula (Mt4.0, v1). The Y-axis shows negative log (P-values) of marker-trait association.

576 Chromosome numbers are illustrated by colors at the bottom of the figures.

577 Fig. 8. A Vann chart of significant loci associated with forage quality resulting from GWAS for

578 quality traits in alfalfa under well-watered (CTL), mild and severe water deficits compared with mean

579 (A) and without mean (B). The numbers of significant loci identified under each treatment were 
580 compared with those of mean values of all treatments, showing the numbers of common (overlapped)

581 and specific loci for different treatments.

582 Fig. 9. Correlation coefficients between means of quality traits and RFV (A) or RFQ (B) and between

583 RFV and crude protein content (C). 
584 Table 1. Analysis of variances of forage quality traits in the panel of 198 alfalfa accessions

\begin{tabular}{|c|c|c|c|c|c|c|c|}
\hline \multicolumn{4}{|c|}{ Analysis of Variance } & \multicolumn{4}{|c|}{ Parameter Estimates } \\
\hline Variable & $\begin{array}{l}\text { Sum of } \\
\text { Squares }\end{array}$ & F Ratio & Prob $>F$ & Estimate & Std Error & t Ratio & Prob $>|t|$ \\
\hline DM & 437.53 & 711.77 & $<.0001$ & 92.19 & 0.09 & 1076.20 & $<.0001$ \\
\hline $\mathrm{CP}$ & 26.72 & 9.45 & 0.0022 & 23.81 & 0.18 & 129.60 & $<.0001$ \\
\hline ADF & 2070.37 & 231.21 & $<.0001$ & 30.82 & 0.33 & 94.25 & $<.0001$ \\
\hline aNDF & 1276.96 & 104.09 & $<.0001$ & 35.90 & 0.38 & 93.80 & $<.0001$ \\
\hline IVTDMD48 & 125.19 & 13.11 & 0.0003 & 81.29 & 0.34 & 240.76 & $<.0001$ \\
\hline dNDF48 & 1176.80 & 548.38 & $<.0001$ & 15.80 & 0.16 & 98.71 & $<.0001$ \\
\hline IVTDMD30 & 577.79 & 45.29 & $<.0001$ & 77.70 & 0.39 & 199.10 & $<.0001$ \\
\hline dNDF30 & 681.32 & 386.22 & $<.0001$ & 12.99 & 0.15 & 89.54 & $<.0001$ \\
\hline ASH & 121.61 & 58.16 & $<.0001$ & 10.69 & 0.16 & 67.68 & $<.0001$ \\
\hline FAT & 17.27 & 920.86 & $<.0001$ & 1.75 & 0.01 & 117.13 & $<.0001$ \\
\hline Lignin & 10.91 & 29.56 & $<.0001$ & 6.36 & 0.07 & 95.74 & $<.0001$ \\
\hline RUP & 911.85 & 220.29 & $<.0001$ & 20.61 & 0.22 & 92.70 & $<.0001$ \\
\hline NEL & 0.29 & 231.21 & $<.0001$ & 0.68 & 0.00 & 174.08 & $<.0001$ \\
\hline TDN & 2364.05 & 231.21 & $<.0001$ & 65.72 & 0.35 & 188.10 & $<.0001$ \\
\hline ENE & 2000.33 & 231.21 & $<.0001$ & 55.94 & 0.32 & 174.08 & $<.0001$ \\
\hline ME & 0.64 & 231.21 & $<.0001$ & 1.08 & 0.01 & 188.10 & $<.0001$ \\
\hline NEM & 0.48 & 230.93 & $<.0001$ & 0.68 & 0.00 & 136.66 & $<.0001$ \\
\hline NEG & 0.37 & 230.73 & $<.0001$ & 0.41 & 0.00 & 93.76 & $<.0001$ \\
\hline DDM & 1256.39 & 231.21 & $<.0001$ & 64.90 & 0.25 & 254.80 & $<.0001$ \\
\hline DRYMI & 22.16 & 114.24 & $<.0001$ & 3.30 & 0.05 & 68.52 & $<.0001$ \\
\hline NDFD48 & 3279.66 & 153.65 & $<.0001$ & 44.12 & 0.50 & 87.40 & $<.0001$ \\
\hline RFV & 130770.31 & 138.82 & $<.0001$ & 164.71 & 3.35 & 49.12 & $<.0001$ \\
\hline NFC & 1158.15 & 121.12 & $<.0001$ & 29.84 & 0.34 & 88.33 & $<.0001$ \\
\hline TDNL & 187.28 & 13.66 & 0.0002 & 60.95 & 0.40 & 150.66 & $<.0001$ \\
\hline DMI1 & 9.74 & 36.29 & $<.0001$ & 3.27 & 0.06 & 57.82 & $<.0001$ \\
\hline RFQ & 17203.35 & 14.21 & 0.0002 & 161.78 & 3.80 & 42.56 & $<.0001$ \\
\hline
\end{tabular}


Table 2. Phenotypic plasticity index for forage quality traits in alfalfa under a water deficit gradient

\begin{tabular}{|c|c|c|c|}
\hline Trait & $\overline{C T L}$ & Mild & Severe \\
\hline RFQ & 0.5504 & 0.7741 & 0.7468 \\
\hline RUP & 0.3873 & 0.4813 & 0.6446 \\
\hline ASH & 0.4946 & 0.6018 & 0.6111 \\
\hline DMI1 & 0.3937 & 0.5843 & 0.5774 \\
\hline RFV & 0.3928 & 0.5471 & 0.5593 \\
\hline NFC & 0.3532 & 0.5720 & 0.5497 \\
\hline NDFD48 & 0.4514 & 0.5759 & 0.5394 \\
\hline ADF & 0.3101 & 0.4789 & 0.4899 \\
\hline dNDF48 & 0.3793 & 0.5358 & 0.4872 \\
\hline Lignin & 0.4362 & 0.3704 & 0.4849 \\
\hline DRYMI & 0.3112 & 0.4498 & 0.4788 \\
\hline aNDF & 0.3112 & 0.4498 & 0.4788 \\
\hline dNDF30 & 0.3751 & 0.5046 & 0.4431 \\
\hline TDNL & 0.2697 & 0.4567 & 0.4019 \\
\hline FAT & 0.4637 & 0.3791 & 0.3793 \\
\hline $\mathrm{CP}$ & 0.3408 & 0.2891 & 0.3667 \\
\hline NEG & 0.3099 & 0.3986 & 0.3483 \\
\hline NEM & 0.2220 & 0.2990 & 0.2658 \\
\hline IVTDMD30 & 0.1986 & 0.2353 & 0.2472 \\
\hline ENE & 0.1749 & 0.2441 & 0.2210 \\
\hline NEL & 0.1750 & 0.2442 & 0.2209 \\
\hline IVTDMD48 & 0.1447 & 0.2054 & 0.2163 \\
\hline TDN & 0.1630 & 0.2290 & 0.2076 \\
\hline $\mathrm{ME}$ & 0.1630 & 0.2290 & 0.2076 \\
\hline DDM & 0.1233 & 0.1768 & 0.1613 \\
\hline DM & 0.0179 & 0.0380 & 0.0289 \\
\hline
\end{tabular}

586 Notes: CTL, well-watered control. Mild, mild water deficit. Severe, severe water deficit 
587 Table 3. Significant markers associated with forage quality traits under well-watered control (CTL),

588 mild water deficit (Mild) and severe water deficit (Severe) in the panel of 198 accessions

\begin{tabular}{|c|c|c|c|c|c|c|c|}
\hline $\begin{array}{l}\text { Treat- } \\
\text { ment }\end{array}$ & Trait & Marker & Chr & P_value & $\mathrm{R}^{2}$ & $\begin{array}{l}\text { Associated with } \\
\text { other traits }\end{array}$ & Annotated gene \\
\hline CTL & ADF & S1_110050752 & 4 & $5.86 \mathrm{E}-05$ & 0.08 & \multicolumn{2}{|c|}{$\begin{array}{l}\text { DDM,ENE,IVTDMD30,IVTDMD48,ME,NEG, } \\
\text { NEL,NEM,CP,TDN }\end{array}$} \\
\hline CTL & DMI1 & S1_305729816 & 7 & $5.68 \mathrm{E}-05$ & 0.11 & $\begin{array}{l}\text { IVTDMD30,IVTDMD4 } \\
\text { 8,NDFD48,CP, } \\
\text { RFQ,TDNL }\end{array}$ & $\begin{array}{l}\text { programmed cell } \\
\text { death protein }\end{array}$ \\
\hline CTL & ADF & S1_231443201 & 7 & $9.34 \mathrm{E}-05$ & 0.08 & \multicolumn{2}{|c|}{ DDM,ENE,ME,NEG,NEL,NEM,TDN,TDNL } \\
\hline CTL & $\mathrm{ASH}$ & S1_276968305 & $\mathrm{U}$ & $5.83 \mathrm{E}-07$ & 0.15 & \multicolumn{2}{|c|}{ FAT,IVTDMD48,NDFD48,TDNL } \\
\hline CTL & IVTDMD48 & S1_351118210 & 6 & $7.44 \mathrm{E}-05$ & 0.11 & \multicolumn{2}{|l|}{ NDFD48,NFC,RFQ,TDNL } \\
\hline CTL & dNDF30 & S1_157382372 & 8 & $8.21 \mathrm{E}-05$ & 0.11 & Lignin,NFC & \\
\hline CTL & DMI1 & S1_176594850 & 5 & $9.97 \mathrm{E}-05$ & 0.10 & DRYMI,FAT & $\begin{array}{l}\text { hypothetical } \\
\text { protein }\end{array}$ \\
\hline CTL & $\mathrm{ASH}$ & S1_220027052 & 7 & $3.15 E-06$ & 0.12 & NFC & \\
\hline$\overline{C T L}$ & $\mathrm{ASH}$ & S1_371197359 & 2 & $4.46 \mathrm{E}-06$ & 0.15 & TDNL & $\begin{array}{l}\text { reticulon-like } \\
\text { protein B2 }\end{array}$ \\
\hline$\overline{C T L}$ & $\mathrm{ASH}$ & S1_7257201 & 1 & $9.57 \mathrm{E}-05$ & 0.08 & TDNL & \\
\hline CTL & FAT & S1_301932961 & $\mathrm{U}$ & $8.36 \mathrm{E}-05$ & 0.10 & TDNL & \\
\hline CTL & NFC & S1_201458525 & 6 & $1.67 \mathrm{E}-05$ & 0.10 & TDNL & \\
\hline CTL & NFC & S1_153379823 & 4 & $4.19 E-06$ & 0.15 & & $\begin{array}{l}\text { cadmium/zinc- } \\
\text { transporting } \\
\text { ATPase }\end{array}$ \\
\hline CTL & $\mathrm{ASH}$ & S1_121767806 & 4 & $6.37 \mathrm{E}-05$ & 0.09 & & \\
\hline CTL & $\mathrm{ASH}$ & S1_271419513 & 8 & 7.47E-06 & 0.11 & & \\
\hline CTL & $\mathrm{ASH}$ & S1_280254383 & $\mathrm{U}$ & 9.57E-05 & 0.10 & & \\
\hline CTL & $\mathrm{ASH}$ & S1_292633486 & $\mathrm{U}$ & $2.14 \mathrm{E}-05$ & 0.11 & & \\
\hline CTL & $\mathrm{ASH}$ & S1_371197348 & U & $5.12 \mathrm{E}-05$ & 0.13 & & \\
\hline CTL & $\mathrm{ASH}$ & S1_60623914 & 2 & $2.29 E-05$ & 0.09 & & \\
\hline CTL & dNDF30 & S1_322005811 & $\mathrm{U}$ & $1.15 \mathrm{E}-05$ & 0.10 & & \\
\hline CTL & IVTDMD30 & S1_62489807 & 2 & $6.63 \mathrm{E}-05$ & 0.09 & & \\
\hline CTL & IVTDMD48 & S1_66277800 & 3 & $9.85 \mathrm{E}-05$ & 0.12 & & \\
\hline CTL & Lignin & S1_333201923 & $\mathrm{U}$ & $7.53 \mathrm{E}-05$ & 0.11 & & \\
\hline CTL & NDFD48 & S1_212677714 & 7 & $9.72 \mathrm{E}-05$ & 0.08 & & \\
\hline CTL & NDFD48 & S1_250094545 & 8 & $6.34 \mathrm{E}-05$ & 0.12 & & \\
\hline CTL & NFC & S1_314670933 & $\mathrm{U}$ & $3.91 \mathrm{E}-05$ & 0.11 & & \\
\hline CTL & $\mathrm{CP}$ & S1_164595549 & 7 & 8.47E-06 & 0.10 & & \\
\hline CTL & $\mathrm{CP}$ & S1_247656456 & 8 & 4.15E-05 & 0.12 & & \\
\hline CTL & $\mathrm{CP}$ & S1_258595951 & 8 & $8.41 \mathrm{E}-05$ & 0.10 & & \\
\hline CTL & $\mathrm{CP}$ & S1_28009323 & 1 & $6.19 \mathrm{E}-05$ & 0.10 & & \\
\hline CTL & $\mathrm{CP}$ & S1_385819739 & $\mathrm{U}$ & $7.88 \mathrm{E}-05$ & 0.08 & & \\
\hline CTL & RUP & S1_110050740 & 7 & $4.92 \mathrm{E}-06$ & 0.11 & & \\
\hline CTL & RUP & S1_185177363 & 5 & $2.30 \mathrm{E}-05$ & 0.12 & & \\
\hline
\end{tabular}




\begin{tabular}{|c|c|c|c|c|c|c|c|}
\hline CTL & RUP & S1_217816246 & 7 & $4.70 \mathrm{E}-05$ & 0.10 & & \\
\hline CTL & TDNL & S1_162648265 & 5 & $1.22 \mathrm{E}-05$ & 0.10 & & \\
\hline CTL & TDNL & S1_316254019 & $\mathrm{U}$ & $1.39 \mathrm{E}-05$ & 0.11 & & \\
\hline CTL & TDNL & S1_373469214 & $\mathrm{U}$ & 4.59E-05 & 0.09 & & \\
\hline CTL & TDNL & S1_378651194 & $\mathrm{U}$ & $1.56 \mathrm{E}-05$ & 0.12 & & \\
\hline CTL & TDNL & S1_63800922 & 3 & $6.22 \mathrm{E}-06$ & 0.14 & & \\
\hline CTL & TDNL & S1_75158591 & 3 & $4.51 \mathrm{E}-05$ & 0.09 & & \\
\hline Mild & $\mathrm{ASH}$ & S1_292679040 & 1 & $2.49 \mathrm{E}-13$ & 0.27 & $\begin{array}{l}\text { dNDF48,NDFD48, } \\
\text { NFC,TDNL }\end{array}$ & $\begin{array}{l}\text { cytochrome P450 } \\
\text { family protein }\end{array}$ \\
\hline Mild & ASH & S1_197238737 & 6 & $5.79 E-16$ & 0.38 & \multicolumn{2}{|c|}{ dNDF48,NDFD48,NFC,RUP,TDNL } \\
\hline Mild & $\mathrm{ASH}$ & S1_136859347 & 4 & $4.05 \mathrm{E}-14$ & 0.31 & NDFD48,NFC,TDNL & \\
\hline Mild & $\mathrm{ASH}$ & S1_300540244 & 7 & $2.14 \mathrm{E}-15$ & 0.38 & NDFD48,NFC,TDNL & $\begin{array}{l}\text { UDP-glucosyl- } \\
\text { transferase family } \\
\text { protein }\end{array}$ \\
\hline Mild & ASH & S1_311409163 & $\mathrm{U}$ & $1.53 \mathrm{E}-10$ & 0.21 & NDFD48,NFC,TDNL & $\begin{array}{l}\text { exostosin family } \\
\text { protein }\end{array}$ \\
\hline Mild & ASH & S1_45016191 & 2 & $4.05 E-07$ & 0.16 & NDFD48,NFC,TDNL & \\
\hline Mild & $\mathrm{ASH}$ & S1_62932631 & 2 & $1.20 \mathrm{E}-14$ & 0.32 & NDFD48,NFC,TDNL & $\begin{array}{l}\text { helix loop helix } \\
\text { DNA-binding } \\
\text { domain protein }\end{array}$ \\
\hline Mild & $\mathrm{ASH}$ & S1_62932652 & 2 & $1.20 \mathrm{E}-14$ & 0.32 & NDFD48,NFC,TDNL & \\
\hline Mild & dNDF30 & S1_50692984 & 2 & $4.72 \mathrm{E}-07$ & 0.16 & dNDF48,ASH,NFC & \\
\hline Mild & $\mathrm{ASH}$ & S1_151845055 & 5 & $5.68 \mathrm{E}-09$ & 0.21 & NFC,TDNL & \\
\hline Mild & $\mathrm{ASH}$ & S1_163809114 & 5 & $1.15 \mathrm{E}-06$ & 0.17 & NFC,TDNL & \\
\hline Mild & $\mathrm{ASH}$ & S1_177465248 & 5 & $2.27 \mathrm{E}-05$ & 0.12 & NFC,TDNL & \\
\hline Mild & $\mathrm{ASH}$ & S1_220027044 & 7 & $8.39 E-06$ & 0.15 & NFC,TDNL & \\
\hline Mild & $\mathrm{ASH}$ & S1_309228882 & 8 & $5.33 \mathrm{E}-08$ & 0.18 & NFC,TDNL & $\begin{array}{l}\text { carotenoid } \\
\text { cleavage } \\
\text { dioxygenase }\end{array}$ \\
\hline Mild & aNDF & S1_366420904 & $\mathrm{U}$ & $7.21 \mathrm{E}-05$ & 0.09 & $\begin{array}{l}\text { IVTDMD30, } \\
\text { IVTDMD48 }\end{array}$ & \\
\hline Mild & $\mathrm{ASH}$ & S1_130145842 & 4 & $3.78 \mathrm{E}-07$ & 0.17 & NFC,TDNL & $\begin{array}{l}\text { RING zinc finger } \\
\text { protein }\end{array}$ \\
\hline Mild & $\mathrm{ASH}$ & S1_163809083 & 5 & $1.10 \mathrm{E}-05$ & 0.14 & NFC,TDNL & \\
\hline Mild & ASH & S1_294827153 & 2 & 5.09E-09 & 0.23 & NFC,TDNL & $\begin{array}{l}\text { auxin-binding } \\
\text { protein ABP19a }\end{array}$ \\
\hline Mild & $\mathrm{ASH}$ & S1_387336049 & 3 & $3.82 \mathrm{E}-07$ & 0.16 & NFC,TDNL & \\
\hline Mild & $\mathrm{ASH}$ & S1_96848449 & 3 & $1.82 \mathrm{E}-06$ & 0.16 & NFC,TDNL & \\
\hline Mild & NFC & S1_380790483 & $\mathrm{U}$ & $1.75 \mathrm{E}-05$ & 0.13 & NFC,TDNL & \\
\hline Mild & dNDF30 & S1_11398797 & 3 & $1.11 \mathrm{E}-06$ & 0.16 & dNDF48 & \\
\hline Mild & dNDF30 & S1_121767803 & 6 & $5.76 \mathrm{E}-07$ & 0.17 & dNDF48 & \\
\hline Mild & dNDF30 & S1_140803955 & 4 & $6.87 E-07$ & 0.16 & dNDF48 & $\begin{array}{l}\text { prolyl 4- } \\
\text { hydroxylase } \\
\text { subunit alpha-like } \\
\text { protein }\end{array}$ \\
\hline
\end{tabular}




\begin{tabular}{|c|c|c|c|c|c|c|c|}
\hline Mild & dNDF30 & S1_20593175 & 1 & $6.68 \mathrm{E}-07$ & 0.16 & dNDF48 & $\begin{array}{l}\text { LRR receptor-like } \\
\text { kinase }\end{array}$ \\
\hline Mild & dNDF30 & S1_255810503 & 8 & $6.88 \mathrm{E}-07$ & 0.16 & dNDF48 & \\
\hline Mild & dNDF30 & S1_323917811 & 6 & $6.48 \mathrm{E}-07$ & 0.16 & dNDF48 & \\
\hline Mild & dNDF30 & S1_324999216 & 5 & $1.04 \mathrm{E}-06$ & 0.16 & dNDF48 & \\
\hline Mild & dNDF30 & S1_328564258 & 8 & $6.50 \mathrm{E}-07$ & 0.16 & dNDF48 & \\
\hline Mild & dNDF30 & S1_352766048 & 7 & 7.37E-07 & 0.16 & dNDF48 & \\
\hline Mild & dNDF30 & S1_368369179 & 1 & $6.26 \mathrm{E}-07$ & 0.16 & dNDF48 & HASTY 1 \\
\hline Mild & dNDF30 & S1_41503160 & 2 & $8.40 \mathrm{E}-05$ & 0.09 & dNDF48 & \\
\hline Mild & dNDF30 & S1_92116984 & 3 & $7.23 \mathrm{E}-08$ & 0.16 & dNDF48 & $\begin{array}{l}\text { OPT family } \\
\text { oligopeptide } \\
\text { transporter }\end{array}$ \\
\hline Mild & dNDF30 & S1_104541975 & 4 & $2.28 \mathrm{E}-07$ & 0.17 & dNDF48 & \\
\hline Mild & $\mathrm{ASH}$ & S1_217816276 & 7 & $5.75 \mathrm{E}-06$ & 0.11 & NFC & $\begin{array}{l}\text { hypothetical } \\
\text { protein }\end{array}$ \\
\hline Mild & ASH & S1_244286074 & 8 & $3.92 \mathrm{E}-05$ & 0.11 & NFC & \\
\hline Mild & $\mathrm{ASH}$ & S1_274178328 & $\mathrm{U}$ & $8.28 \mathrm{E}-08$ & 0.19 & NFC & $\begin{array}{l}\text { E3 ubiquitin- } \\
\text { protein ligase } \\
\text { XBOS32 }\end{array}$ \\
\hline Mild & $\mathrm{ASH}$ & S1_97771859 & 3 & $1.66 \mathrm{E}-05$ & 0.11 & NFC & \\
\hline Mild & ASH & S1_146032006 & 4 & $1.34 \mathrm{E}-05$ & 0.11 & TDNL & \\
\hline Mild & IVTDMD48 & S1_104542260 & 4 & $8.56 \mathrm{E}-05$ & 0.09 & TDNL & \\
\hline Mild & IVTDMD48 & S1_41574028 & 2 & $9.35 \mathrm{E}-05$ & 0.12 & NDFD48 & \\
\hline Mild & $\mathrm{ASH}$ & S1_109199212 & 4 & $9.23 E-05$ & 0.12 & & \\
\hline Mild & $\mathrm{ASH}$ & S1_255810496 & 8 & $5.06 \mathrm{E}-06$ & 0.14 & & \\
\hline Mild & $\mathrm{ASH}$ & S1_274180547 & $\mathrm{U}$ & $1.97 \mathrm{E}-05$ & 0.10 & & \\
\hline Mild & $\mathrm{ASH}$ & S1_319319782 & 1 & $7.42 \mathrm{E}-06$ & 0.11 & & $\begin{array}{l}\text { IQ calmodulin- } \\
\text { binding motif } \\
\text { protein }\end{array}$ \\
\hline Mild & $\mathrm{ASH}$ & S1_343058809 & $\mathrm{U}$ & $2.88 \mathrm{E}-05$ & 0.13 & & \\
\hline Mild & $\mathrm{ASH}$ & S1_344523780 & $\mathrm{U}$ & $6.40 \mathrm{E}-05$ & 0.09 & & \\
\hline Mild & $\mathrm{ASH}$ & S1_380790483 & 7 & $4.92 \mathrm{E}-08$ & 0.19 & & $\begin{array}{l}\text { feronia receptor- } \\
\text { like kinase }\end{array}$ \\
\hline Mild & $\mathrm{ASH}$ & S1_46291954 & 2 & $1.56 \mathrm{E}-05$ & 0.15 & & \\
\hline Mild & dNDF30 & S1_73439383 & 3 & $9.68 \mathrm{E}-05$ & 0.12 & & \\
\hline Mild & FAT & S1_251411374 & 8 & $8.22 \mathrm{E}-05$ & 0.09 & & \\
\hline Mild & Lignin & S1_77578936 & 3 & $2.58 \mathrm{E}-05$ & 0.10 & & \\
\hline Mild & NFC & S1_4134311 & 1 & 4.89E-05 & 0.09 & & \\
\hline Mild & NFC & S1_95240267 & 7 & $1.50 \mathrm{E}-06$ & 0.15 & & \\
\hline Severe & DMI1 & S1_174013573 & 5 & $4.78 \mathrm{E}-05$ & 0.10 & DRYMI,FAT,RFQ,RFV & \\
\hline Severe & $\mathrm{ASH}$ & S1_295104600 & 8 & $3.83 \mathrm{E}-12$ & 0.25 & NDFD48,NFC,TDNL & \\
\hline Severe & DMI1 & S1_223418326 & 7 & $6.33 \mathrm{E}-05$ & 0.09 & DRYMI,RFQ,RFV & \\
\hline Severe & $\mathrm{ASH}$ & S1_3090630 & 1 & $2.17 E-05$ & 0.10 & dNDF30,dNDF48 & \\
\hline Severe & ASH & S1_368127329 & 7 & $2.40 \mathrm{E}-07$ & 0.16 & NFC,TDNL & \\
\hline
\end{tabular}




\begin{tabular}{|c|c|c|c|c|c|c|c|}
\hline Severe & $\mathrm{ASH}$ & S1_54810936 & 2 & 5.67E-06 & 0.13 & NFC,TDNL & \\
\hline Severe & NFC & S1_380541834 & $\mathrm{U}$ & $3.38 \mathrm{E}-05$ & 0.12 & $\mathrm{ASH}$ & \\
\hline Severe & ASH & S1_108148173 & 4 & $4.90 \mathrm{E}-07$ & 0.17 & NFC & $\begin{array}{l}\text { TIR-NBS-LRR } \\
\text { family protein }\end{array}$ \\
\hline Severe & $\mathrm{ASH}$ & S1_238285037 & 7 & $6.46 \mathrm{E}-05$ & 0.10 & NFC & \\
\hline Severe & ASH & S1_259198355 & 8 & $5.03 \mathrm{E}-07$ & 0.15 & NFC & $\begin{array}{l}\text { interferon- } \\
\text { induced } \\
\text { guanylate-binding } \\
\text { protein }\end{array}$ \\
\hline Severe & ASH & S1_261323300 & 8 & $3.13 \mathrm{E}-06$ & 0.14 & NFC & $\begin{array}{l}\text { peroxidase family } \\
\text { protein }\end{array}$ \\
\hline Severe & ASH & S1_288329783 & $\mathrm{U}$ & $5.02 \mathrm{E}-06$ & 0.13 & NFC & \\
\hline Severe & $\mathrm{ASH}$ & S1_303744644 & $\mathrm{U}$ & 4.95E-06 & 0.13 & NFC & \\
\hline Severe & $\mathrm{ASH}$ & S1_314656475 & $\mathrm{U}$ & 4.29E-06 & 0.13 & NFC & \\
\hline Severe & ASH & S1_351945756 & $\mathrm{U}$ & $1.06 \mathrm{E}-05$ & 0.14 & NFC & \\
\hline Severe & ASH & S1_36657304 & 2 & 6.07E-06 & 0.13 & NFC & \\
\hline Severe & ASH & S1_86892057 & 3 & 4.10E-06 & 0.14 & NFC & \\
\hline Severe & $\mathrm{ASH}$ & S1_94485521 & 3 & 3.17E-06 & 0.14 & NFC & \\
\hline Severe & ASH & S1_42165100 & 2 & 4.07E-05 & 0.12 & TDNL & \\
\hline Severe & ASH & S1_138061496 & 4 & $5.62 E-05$ & 0.11 & & \\
\hline Severe & ASH & S1_198430876 & 6 & $1.36 \mathrm{E}-06$ & 0.12 & & \\
\hline Severe & $\mathrm{ASH}$ & S1_20159111 & 1 & $1.27 \mathrm{E}-05$ & 0.14 & & \\
\hline Severe & $\mathrm{ASH}$ & S1_20221412 & 1 & 7.64E-06 & 0.13 & & \\
\hline Severe & ASH & S1_208437908 & 7 & $3.99 \mathrm{E}-07$ & 0.16 & & \\
\hline Severe & ASH & S1_259969207 & 8 & $1.18 \mathrm{E}-05$ & 0.14 & & \\
\hline Severe & ASH & S1_314502177 & $\mathrm{U}$ & $4.76 \mathrm{E}-06$ & 0.13 & & \\
\hline Severe & ASH & S1_380541834 & $\mathrm{U}$ & $6.82 \mathrm{E}-06$ & 0.14 & & \\
\hline Severe & $\mathrm{ASH}$ & S1_62529190 & 2 & $3.89 \mathrm{E}-06$ & 0.13 & & \\
\hline Severe & ASH & S1_66246980 & 3 & $6.79 \mathrm{E}-05$ & 0.09 & & \\
\hline Severe & ASH & S1_97087353 & 3 & $1.64 \mathrm{E}-06$ & 0.14 & & \\
\hline Severe & FAT & S1_152463122 & 5 & $5.53 \mathrm{E}-07$ & 0.16 & & \\
\hline Severe & FAT & S1_213944479 & 7 & $9.20 \mathrm{E}-06$ & 0.15 & & \\
\hline Severe & FAT & S1_221806152 & 7 & $3.65 \mathrm{E}-05$ & 0.10 & & \\
\hline Severe & FAT & S1_260532035 & 8 & $4.56 \mathrm{E}-05$ & 0.09 & & \\
\hline Severe & FAT & S1_310998070 & 1 & $2.79 \mathrm{E}-07$ & 0.15 & & $\begin{array}{l}\text { RNA-binding } \\
\text { (RRM/RBD/RNP } \\
\text { motif) family } \\
\text { protein }\end{array}$ \\
\hline Severe & FAT & S1_323399172 & $\mathrm{U}$ & $8.83 \mathrm{E}-05$ & 0.08 & & \\
\hline Severe & FAT & S1_68331276 & 3 & $5.32 \mathrm{E}-07$ & 0.15 & & \\
\hline Severe & NFC & S1_313299937 & $\mathrm{U}$ & $1.99 \mathrm{E}-05$ & 0.10 & & \\
\hline Severe & RUP & S1_323002939 & $\mathrm{U}$ & $6.01 \mathrm{E}-05$ & 0.09 & & \\
\hline
\end{tabular}



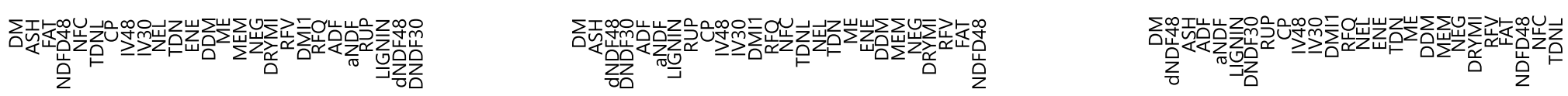

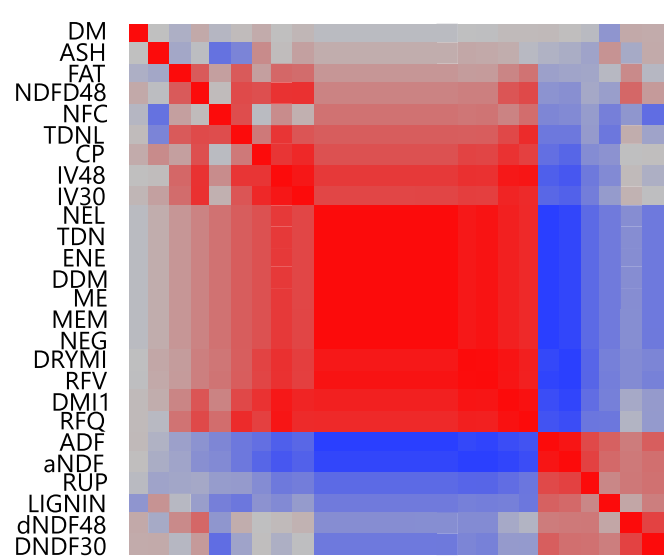

CTL

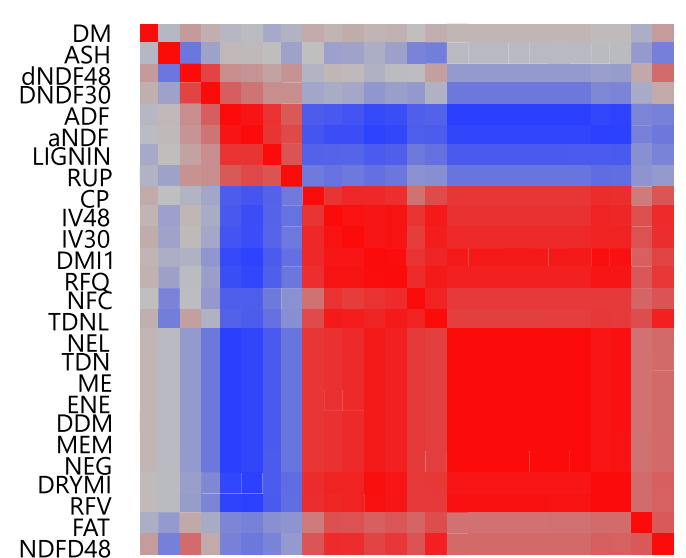

Mild drought

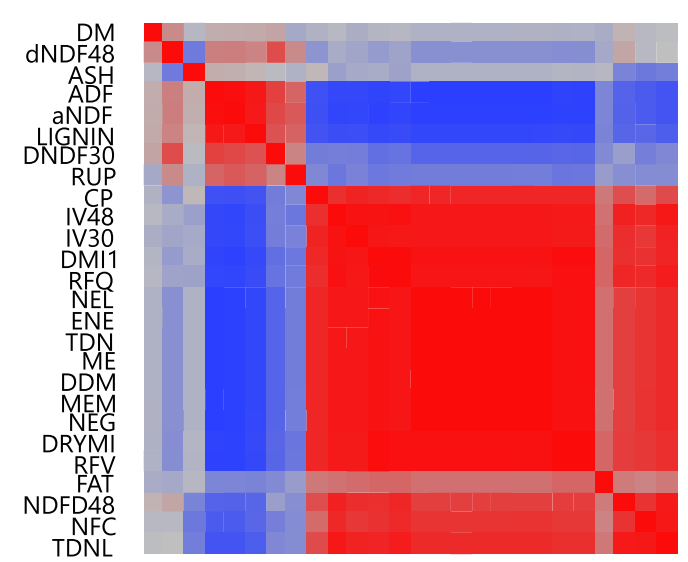

Severe drought 


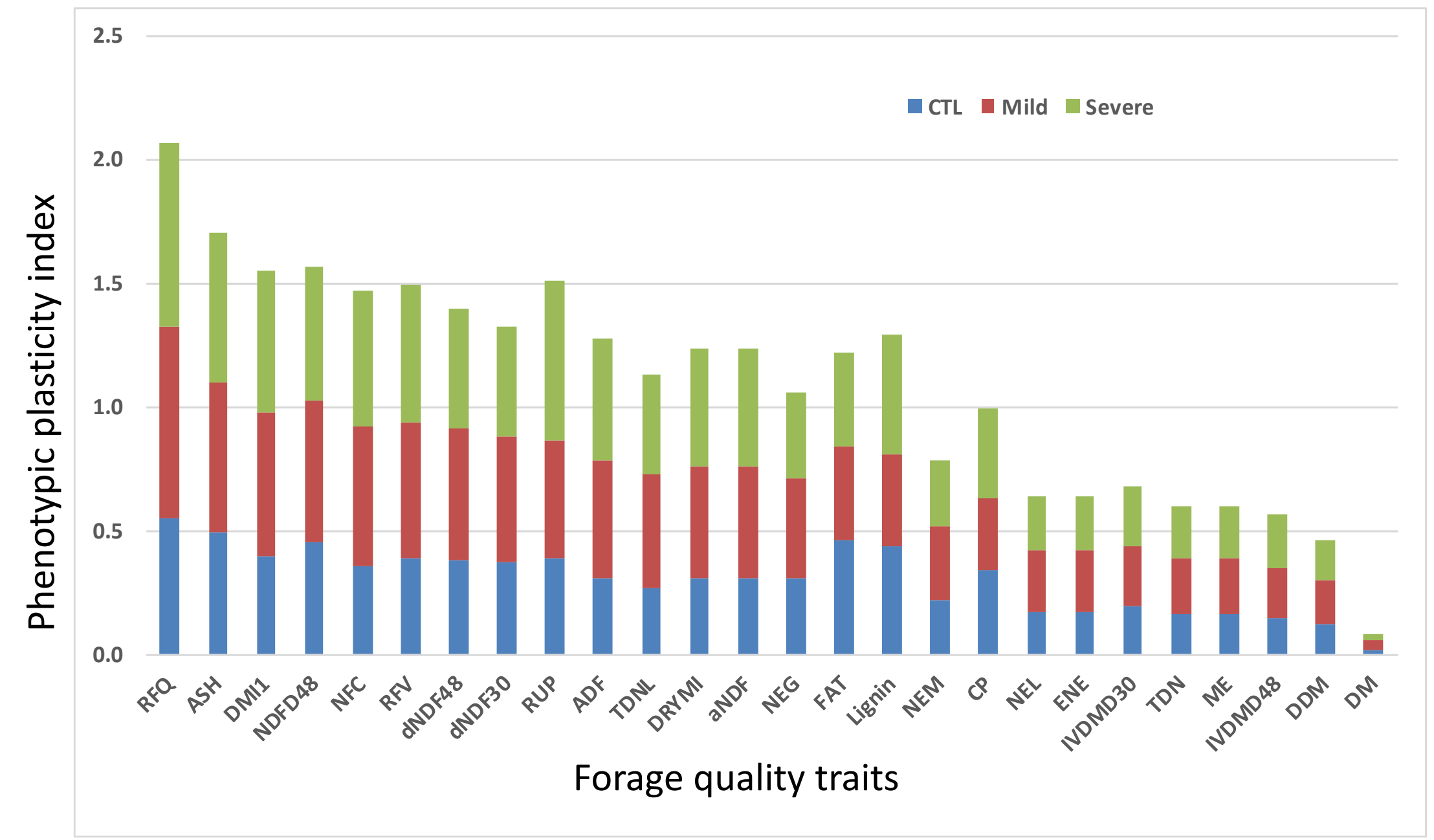




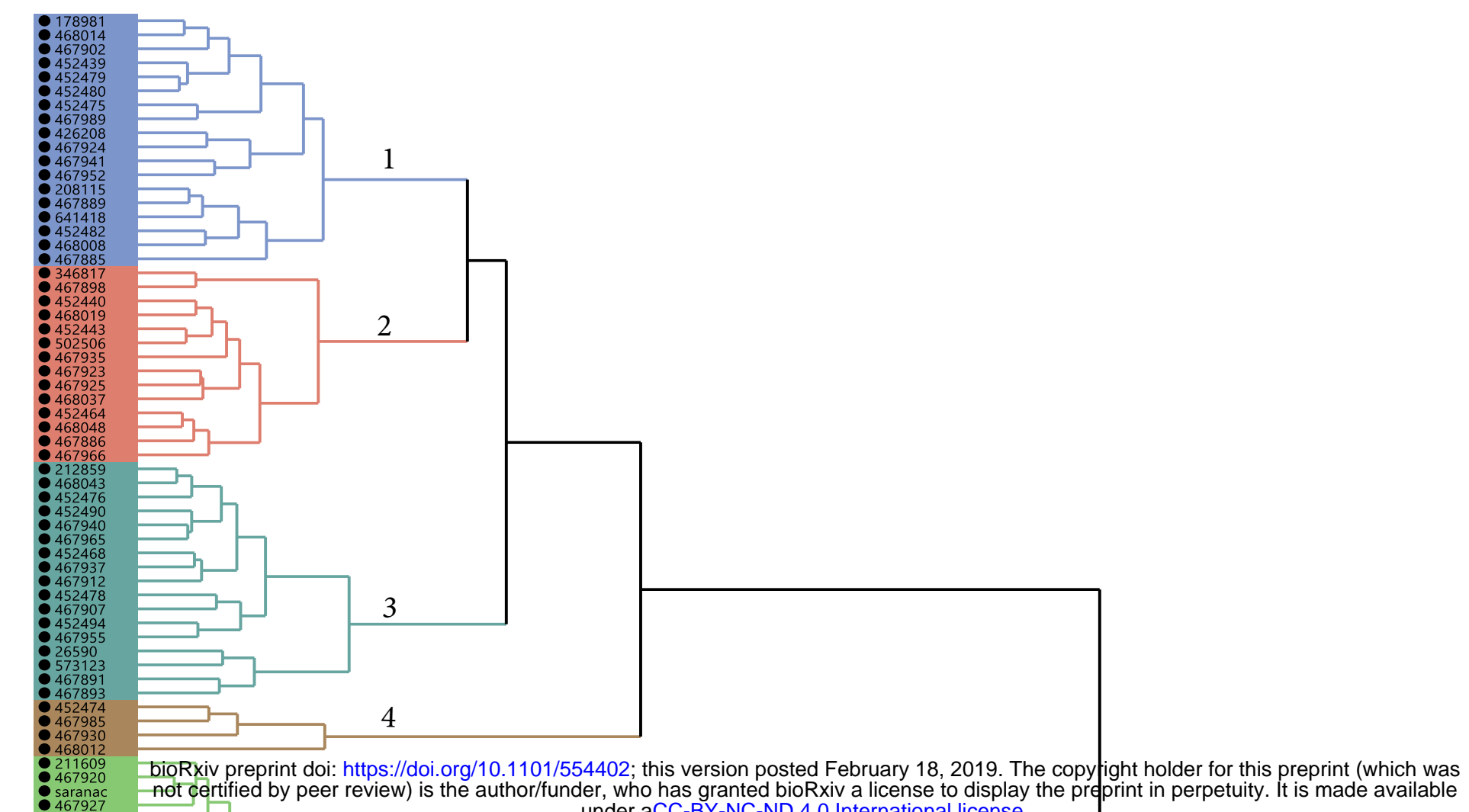
. lay the preprint in perpetuity. It is made available under aCC-BY-NC-ND 4.0 International license.

Higher quality 


\section{Expected -Log(P-Value) vs. -Log(P-Value)}

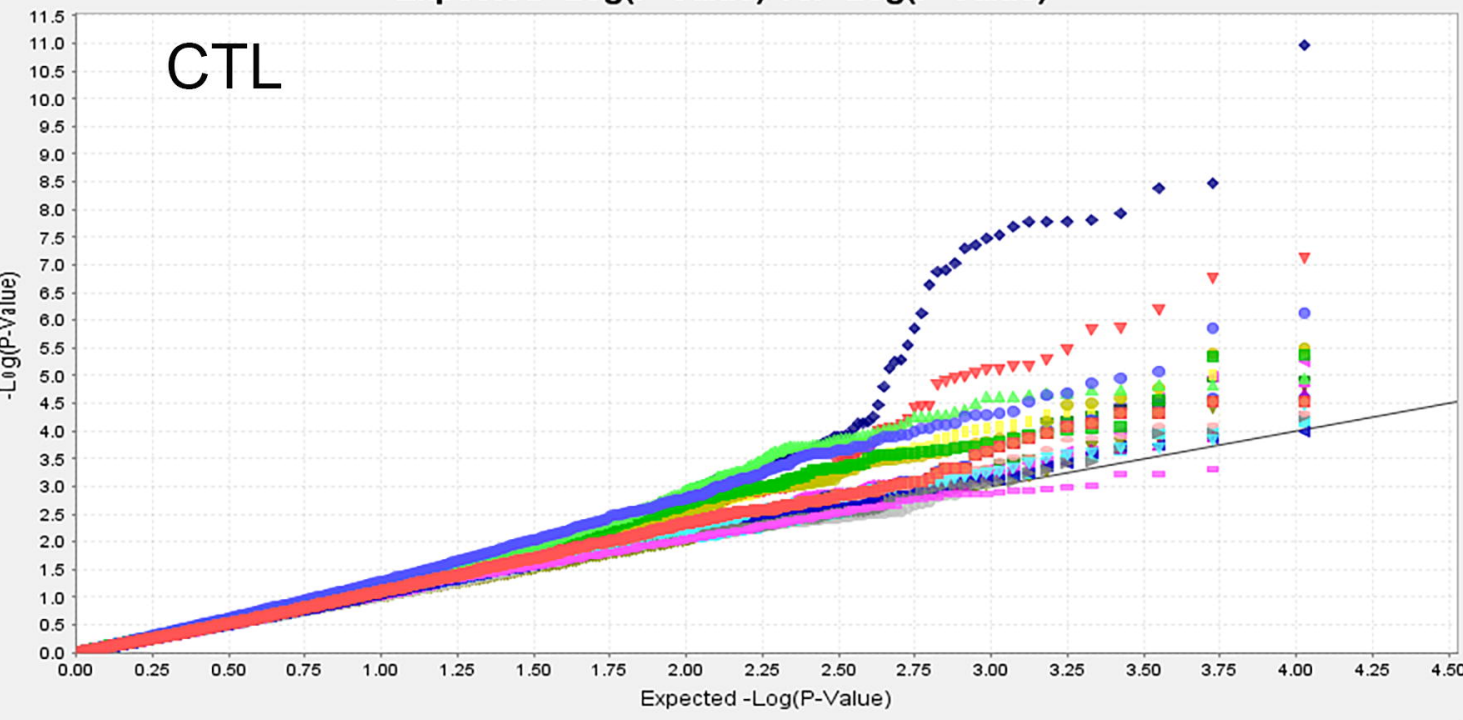

$\because \mathrm{ADF} \bullet \mathrm{ASH} \triangle \mathrm{CP} \quad \mathrm{DDM}=\mathrm{DM} \vee \mathrm{DMl}=\mathrm{DNDF} 30>\mathrm{DRYMI} \| \mathrm{ENE} \triangleleft \mathrm{FAT}=\mathrm{IV} 30 \bullet \mathrm{N} 48 \Delta \mathrm{LIGNIN} \bullet \mathrm{ME}=\mathrm{MEM}$

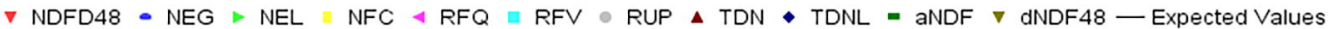

\section{Expected -Log(P-Value) vs. -Log(P-Value)}

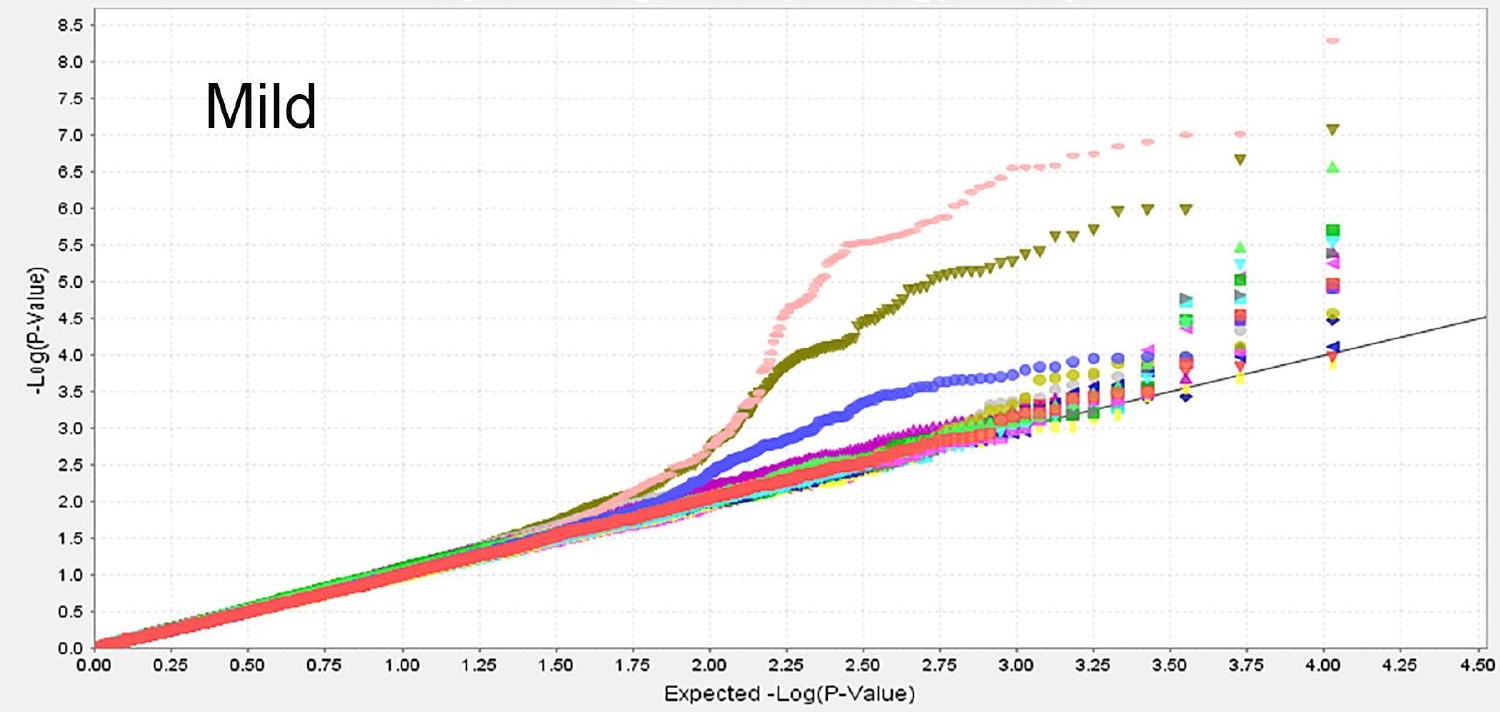

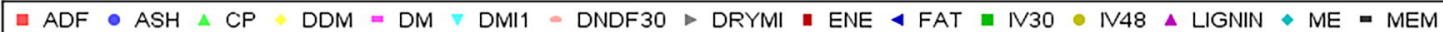

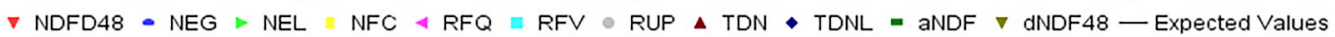

\section{Expected -Log(P-Value) vs. -Log(P-Value)}

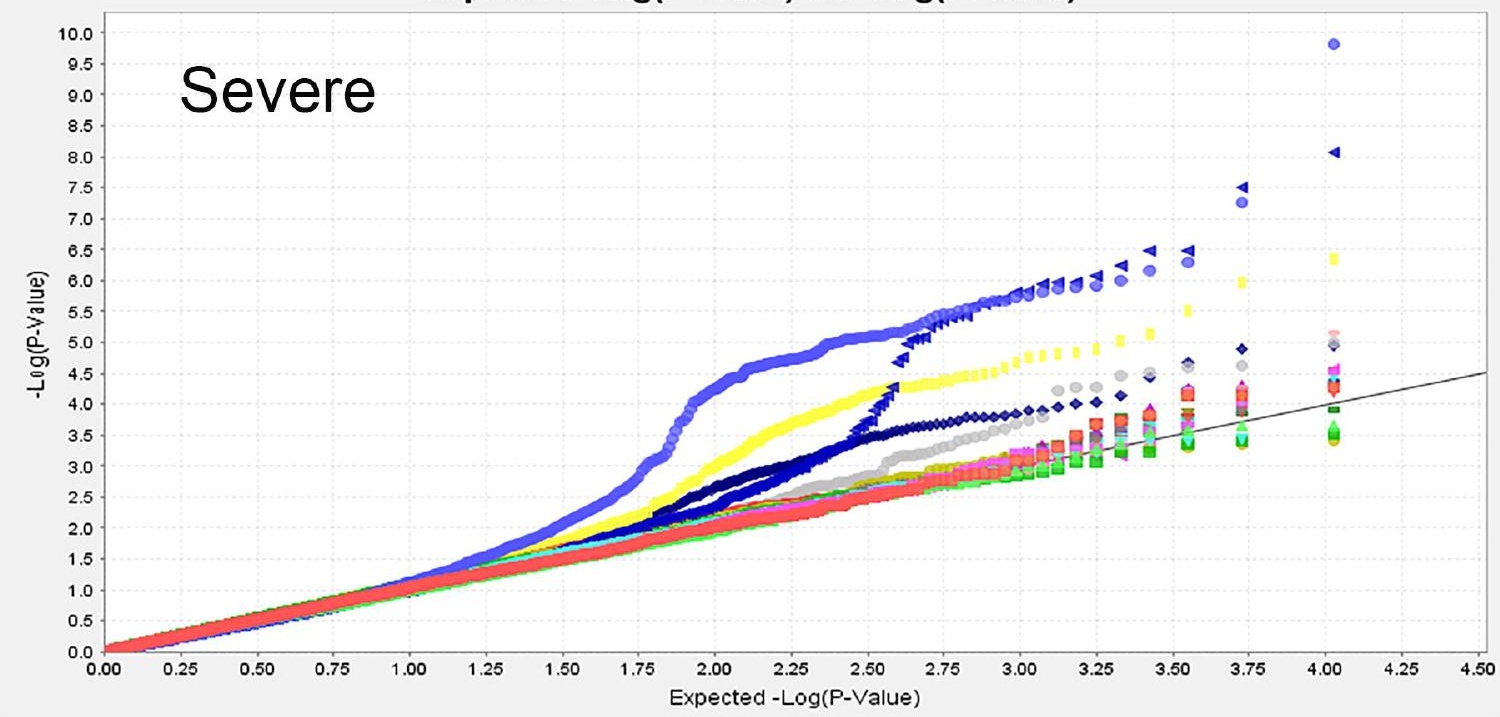

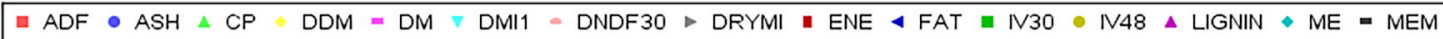

$\nabla \mathrm{NDFD} 48-\mathrm{NEG}>\mathrm{NEL}\|\mathrm{NFC} \triangleleft \mathrm{RFQ}\| \mathrm{RFV} \bullet \mathrm{RUP} \Delta \mathrm{TDN} \bullet \mathrm{TDNL}=$ aNDF $\nabla$ dNDF48 - Expected Values 


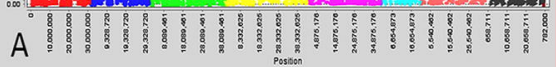

P-Values by Chromosome for ASH

을

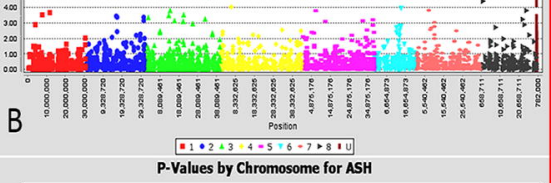

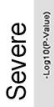

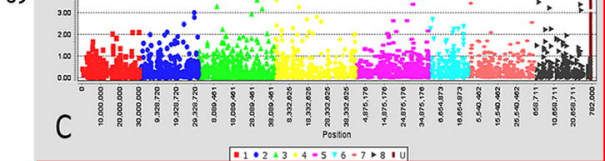

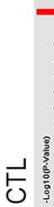

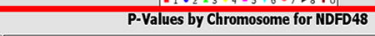

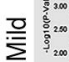

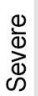

D.

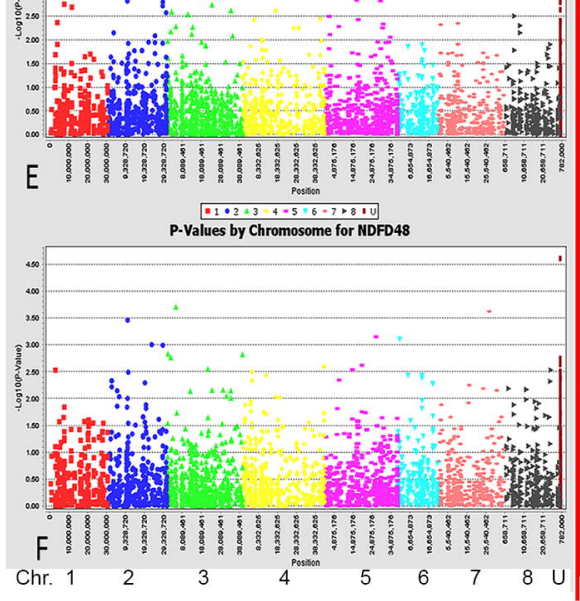

P-Values by Chromosome for NDFD48

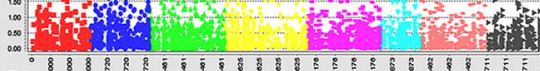

D

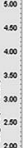

G
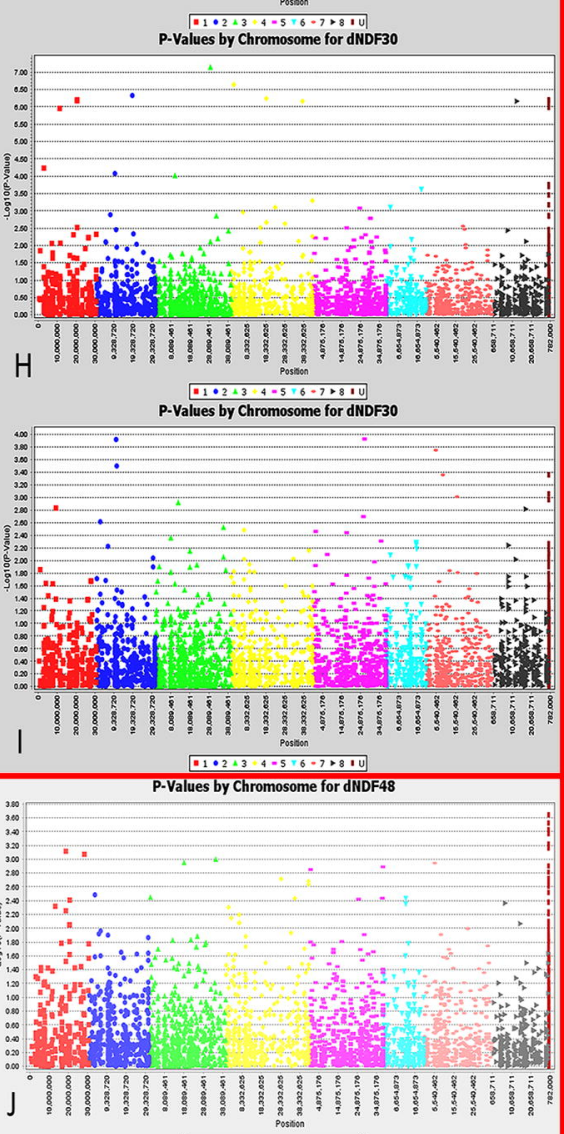

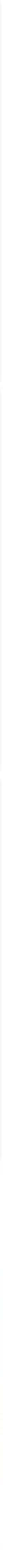

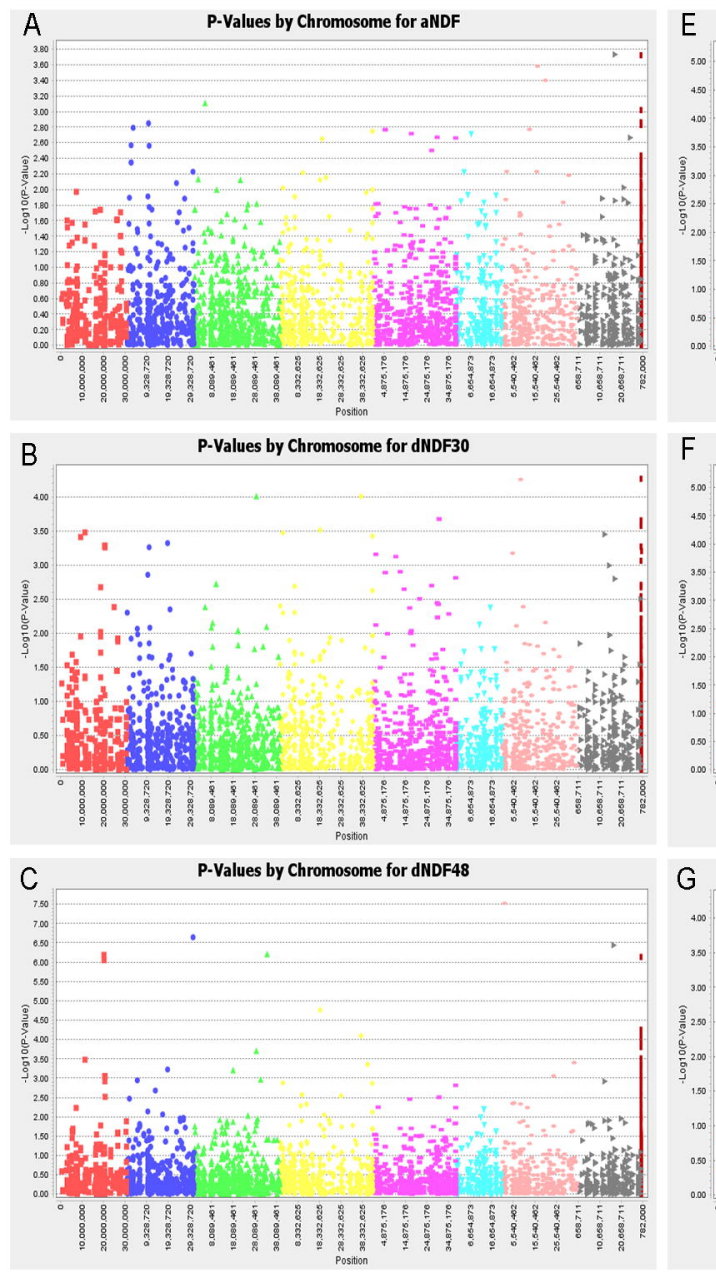

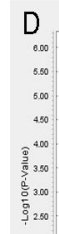$$
\text { D }
$$

P-Values by Chromosome for NDFD48

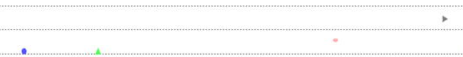

\section{E P.Values by Chromosome for LGNIII}

P-Values by Chromosome for PROTEIN

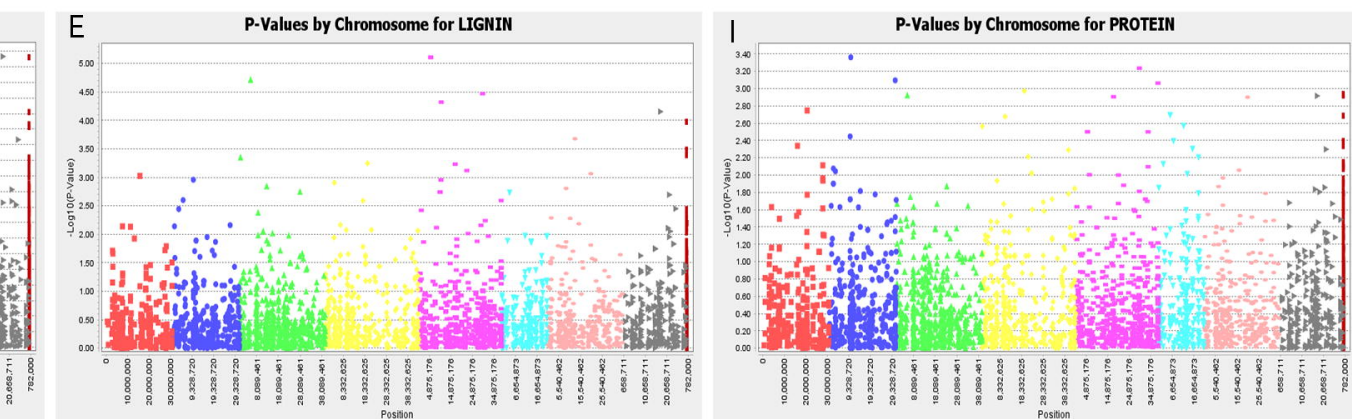

P.Values by Chromosome for NFC
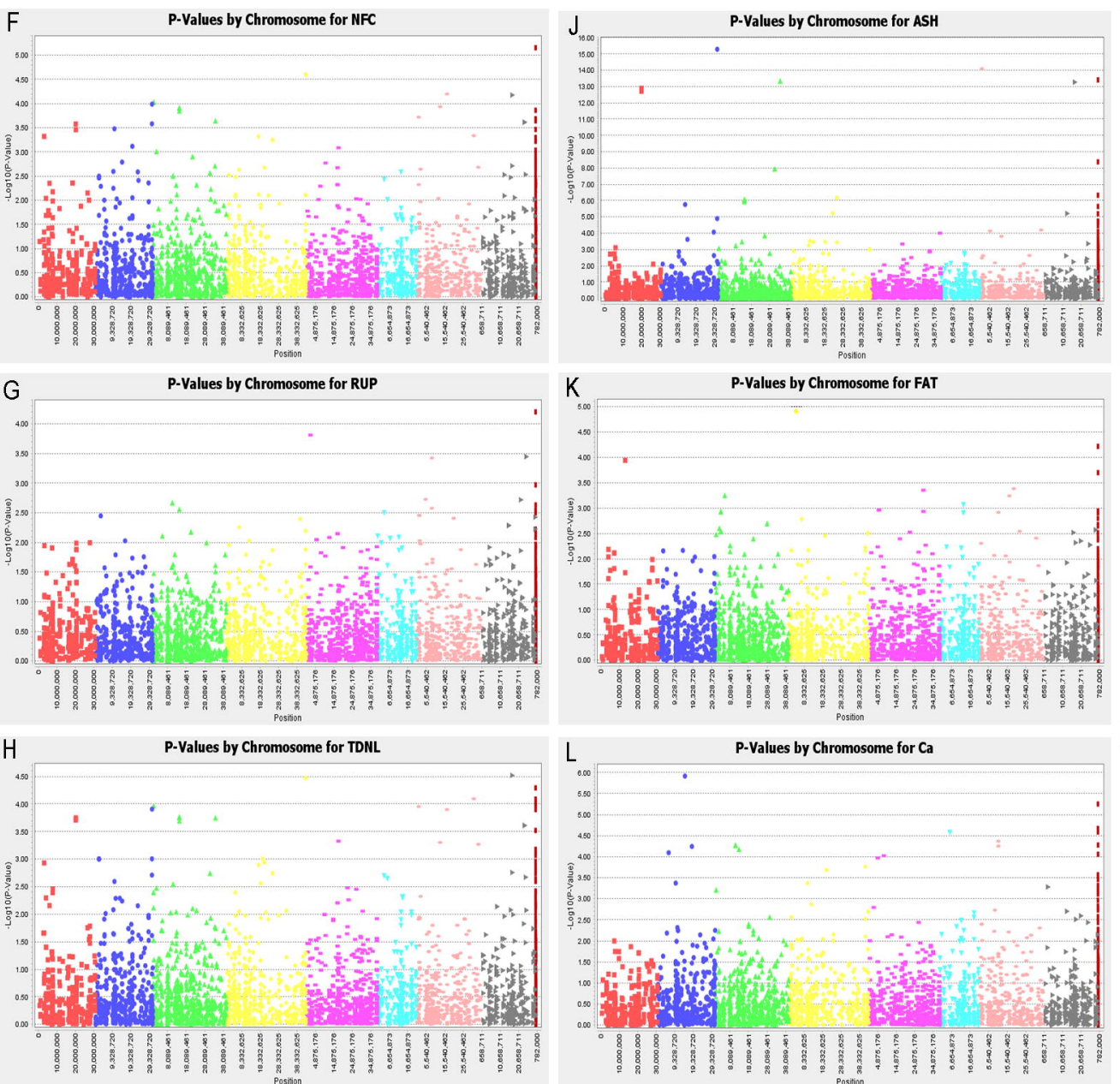

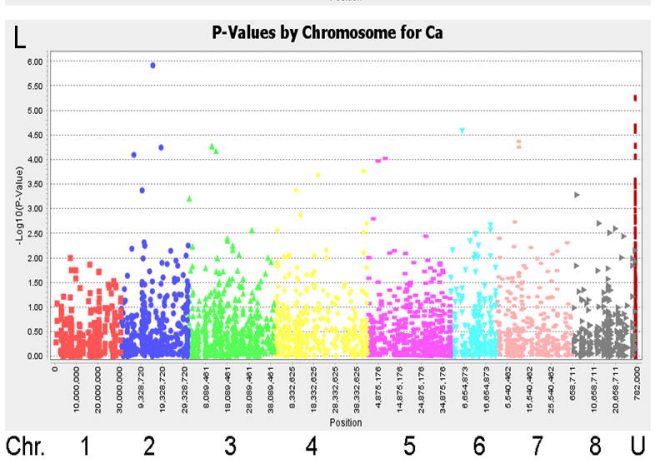

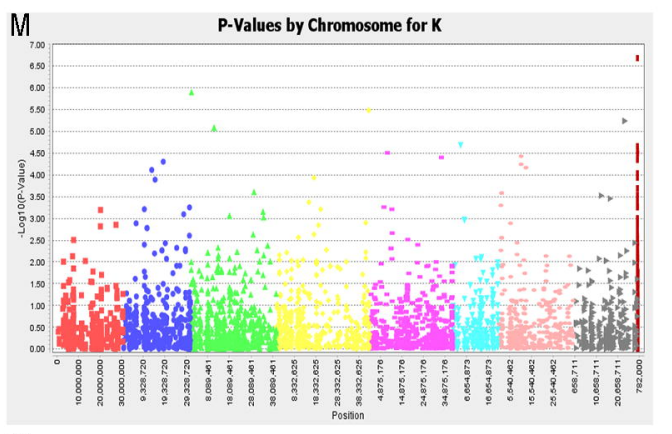
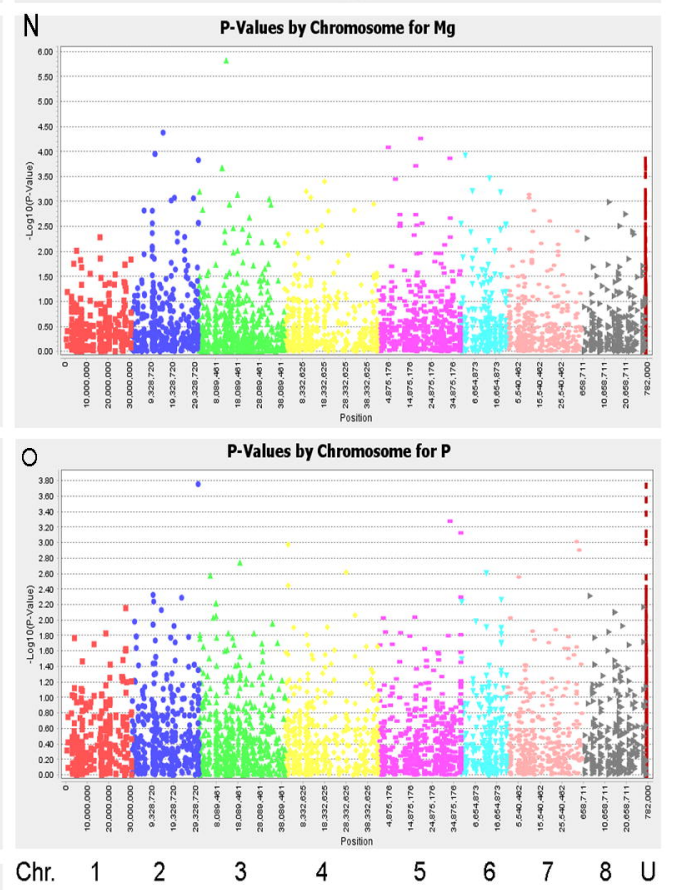

Chr.

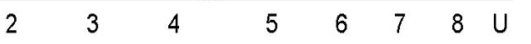



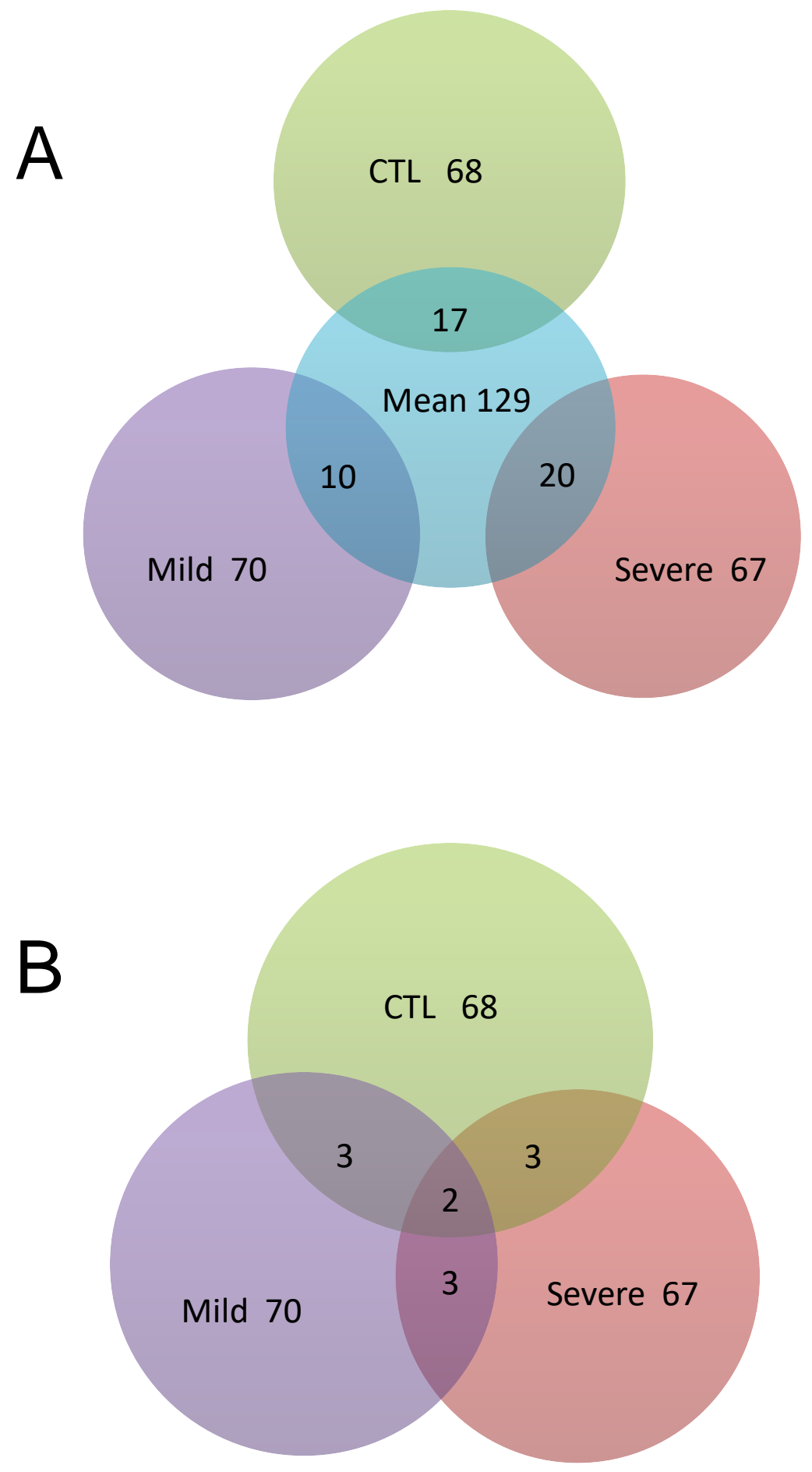
bioRxiv preprint doi: https://doi.org/10.1101/554402; this version posted February 18,2019 . The copyright holder for this preprint (which not certified by peer review) is the author/funder, who has granted bioRxiv a license to display the preprint in perpetuity. It is made availa under aCC-BY-NC-ND 4.0 International license.
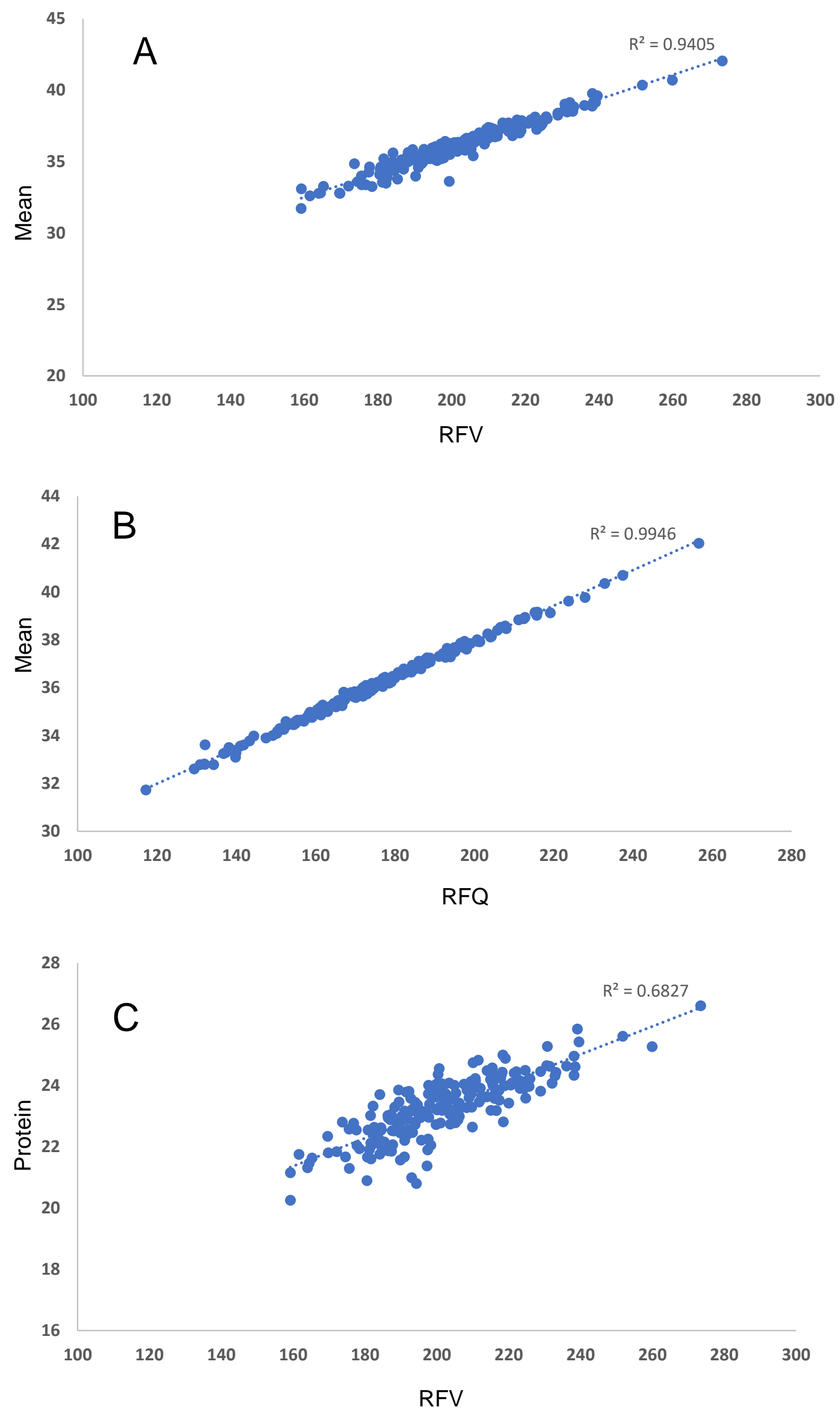